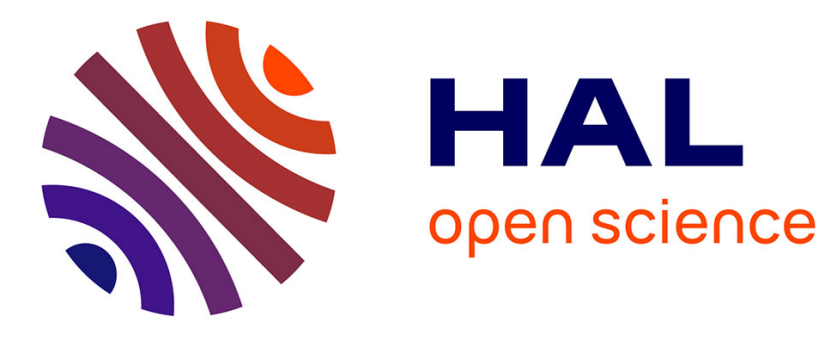

\title{
Impact of stylolites on the mechanical strength of limestone
}

Patrick Baud, Alexandra Rolland, Michael Heap, Tao Xu, Marion Nicolé, Thomas Ferrand, Thierry Reuschle, Renaud Toussaint, Nathalie Conil

\section{To cite this version:}

Patrick Baud, Alexandra Rolland, Michael Heap, Tao Xu, Marion Nicolé, et al.. Impact of stylolites on the mechanical strength of limestone. Tectonophysics, 2016, 690, Part A, pp.4-20. 10.1016/j.tecto.2016.03.004 . hal-01340884

\section{HAL Id: hal-01340884 \\ https://hal.science/hal-01340884}

Submitted on 15 May 2019

HAL is a multi-disciplinary open access archive for the deposit and dissemination of scientific research documents, whether they are published or not. The documents may come from teaching and research institutions in France or abroad, or from public or private research centers.
L'archive ouverte pluridisciplinaire $\mathbf{H A L}$, est destinée au dépôt et à la diffusion de documents scientifiques de niveau recherche, publiés ou non, émanant des établissements d'enseignement et de recherche français ou étrangers, des laboratoires publics ou privés. 


\section{Impact of stylolites of the mechanical strength of limestone}

\section{Patrick Baud ${ }^{1}$, Alexandra Rolland ${ }^{1}$, Michael Heap ${ }^{1}$, Tao $\mathrm{Xu}^{2}$, Marion Nicolé ${ }^{1}$, Thomas} Ferrand $^{3}$, Thierry Reuschlé ${ }^{1}$, Renaud Toussaint ${ }^{1}$, Nathalie Conil ${ }^{4}$

${ }^{1}$ Institut de Physique du Globe de Strasbourg (UMR 7516 CNRS, Université de Strasbourg/EOST), 5 rue René Descartes F-67084 Strasbourg Cedex, France.

\section{${ }^{2}$ College of resources and Civil Engineering, Northeastern University, Shenyang, China}

${ }^{3}$ Département de Géologie, Ecole Normale Supérieure, Paris, France

${ }^{4}$ ANDRA, Bure, France

* Corresponding author

\section{ABSTRACT}

We performed series of uniaxial compression tests on samples of microporous carbonates from the formations surrounding the ANDRA Underground Research Laboratory in Bure, France. Sedimentary stylolites are pervasive in these formations. We show that the porosity in the vicinity of the stylolites is always larger than that of the host rocks. As a result, our new mechanical data reveal that samples with a stylolite are always significantly weaker with respect to the adjacent stylolite-free material. However the presence of a stylolite in different orientations (with respect to the direction of loading) did not result in any mechanical anisotropy. Numerical simulations using a 2D finite element code suggest that the weakening induced by the presence of a stylolite is mostly due to the higher porosity and the higher level of heterogeneity in and around the stylolite, while the absence of mechanical anisotropy is due to the roughness of the stylolite. While the presence of stylolites weakens carbonate rocks, stylolites only act as planes of weakness when their thickness exceeds a certain threshold (about $5 \mathrm{~mm}$ ). 


\section{Introduction}

Stylolites are the product of intergranular pressures-solution and are pervasive in sedimentary formations. They have been described in carbonates (Stockdale, 1943; Park and Schot, 1968; Bathurst, 1971), sandstones (Heald, 1955; Baron and Parnell, 2007), and shales (Rutter, 1983). They appear as column-and-socket interdigitation features (Nenna and Aydin, 2011; Croizé et al., 2013) and are filled with insoluble elements such as organic matter, oxides, or clay particles (Nelson, 1983). Stylolites grow orthogonal to the major principal stress and are often divided in two groups: sedimentary stylolites oriented sub-horizontally to bedding (i.e., those that form due to overburden stresses) and tectonic stylolites (perpendicular or oblique to bedding).

Stylolites have interested geoscientists for now almost a century primarily because, as compaction localization features, they could potentially impact fluid flow at various scales. Until recently, prevalent views on this matter were that stylolites were barriers to fluid flow (see for example Dunnington, 1967). Recent experimental studies revealed however that stylolites in limestones do not influence permeability when they are oriented perpendicular to fluid flow but could in some cases act as conduits when orientated parallel to flow (Lind et al., 1994; Heap et al. 2014a; Rustichelli et al., 2015). In the last decade, several studies also attempted to use stylolites as palaeostress gauges by linking their morphology to in situ stresses (e.g., Schmittbuhl et al., 2004; Rolland et al., 2012).

In situations where stylolites are abundant, another outstanding question important for reservoir/aquifer production and a wide variety of geotechnical applications is their impact on the mechanical strength and rheology of sedimentary formations. This question raised less attention from the scientific community perhaps because its answer appeared somehow obvious. The prevalent views are that the presence of stylolites significantly weakens rocks (Yates and Chakrabarti, 1998; Larbi, 2003; Özvan et al., 2011), that stylolites are natural 
planes of weakness in sedimentary formations (Nicholson and Nicholson, 2000; Pires et al., 2010), and that they induce a significant mechanical anisotropy (Rashed and Sediek, 1997). The fact that stylolites weaken a rock mass is supported by many observations in quarries. López-Buendía et al. (2013), for example, noted that more than $95 \%$ of the breakages affecting the Crema Marfil marble at thin dimensions in a quarry were due to stylolites. Although very low strength was reported in Brazilian tests on the same material with open stylolites (López-Buendía et al., 2013), no study has, to our knowledge, systematically quantified the impact of stylolites on rock strength. One reason is probably that, in both field and laboratory contexts, the opening of the stylolites due to drilling, cutting, or depressurization, is a major issue and there is always some ambiguity whether the observed effect could in fact not primarily be due to some significant microcracking/fracturing associated to the stylolites and not to the structure itself. To what extent are stylolites planes of weakness if they are not open? Do they induce any mechanical anisotropy in that case, and is it possible to systematically quantify some related weakening, if it exists at all? To answer these questions we performed series of uniaxial compression tests on samples prepared from cores taken from a borehole drilled in a limestone formation in the Paris Basin. Stylolites are abundant in this formation and Heap et al. (2014a) recently showed that it is possible to prepare samples in various orientations without opening the stylolites. We are therefore able to systematically compare the mechanical behavior of these limestones with and without stylolites. Guided by new petrophysical measurements and microstructural observations, numerical modelling was used to interpret our mechanical data and clarify the role of stylolites on the brittle strength of carbonate rocks.

\section{Material studied and experimental set-up}

\subsection{Material origin and preparation of the samples}


In this study, we focused on Oxfordian limestones from the Eastern part of the Paris Basin. Several boreholes were drilled surrounding the ANDRA (French agency for nuclear waste disposal) Underground Research Laboratory (URL) near the town of Bure, France. All the limestones studied here are from the same borehole (EST205) and belong to units located above the URL, which is built within a layer of claystone (see Rolland et al., 2014 for details). Stylolites are abundant in most of the retrieved core (Fig. 1a). The larger stylolites (of centimeter size) were open in all cases, probably due to the depressurization upon retrieval. For this study, we focused on sedimentary stylolites and selected zones presenting regularly spaced closed stylolites surrounded by sufficient reference stylolite-free material to be used for comparison. The typical distance between the studied stylolite and the stylolite-free material was about $10 \mathrm{~cm}$. We avoided zones with large heterogeneities, anostomosing stylolites, and stylolites with tilted teeth. We also disregarded partially open stylolites that we could easily spot from the high resolution pictures of Rolland (2013). Because of these quite restrictive criteria, we could not sample the available cores at regular interval of depths. We focused on 6 different depths between 158 and $364 \mathrm{~m}$. The geological and textural details of these layers, named for simplicity in this study O1 to O6, are given in Table 1, based on the previous systematic study of André (2003). The studied units are grainstones, wackstones, and packstones. The stylolites in these different layers show different morphologies, studied in detail by Rolland et al. (2014). In particular, the amplitude of the teeth was observed to be quite variable, from 1 milimeter (Fig. 1b) to a centimeter and sometimes more (Fig. 1c).

Figure 1

Table 1

Cylindrical samples nominally $4 \mathrm{~cm}$ long and $2 \mathrm{~cm}$ in diameter with and without stylolites were prepared from the $10 \mathrm{~cm}$ diameter cores (Fig. 2a-b). For the samples with stylolites, two 
orientations were cored: orthogonal and parallel to the stylolite plane. Where possible, several samples at an oblique orientation $\left(\sim 60^{\circ}\right)$ were also prepared (Fig. $\left.2 \mathrm{c}\right)$. At each selected depth, stylolites with different morphologies were encountered (Rolland et al., 2014). We only grouped results on stylolites that showed common morphological attributes and when possible obtained all the data from the same stylolite. This preparation phase was challenging and coring in three different orientations often minimized the number of cores we could prepare from a given length of core. Further, cutting and drilling into the cores occasionally revealed large heterogeneities, local variations in stylolite orientation, teeth of very high amplitude (with respect to the sample size), and additional stylolites invisible from the surface of the cores. Additionally, some stylolites opened during the sample preparation process. In the end, more than $25 \%$ of the prepared samples had to be disregarded.

\section{Figure 2}

\subsection{Experimental procedure}

All samples were first dried in vacuum at $40^{\circ} \mathrm{C}$ for a minimum of $48 \mathrm{~h}$. In this study we performed "dry" (samples vacuumed at $40{ }^{\circ} \mathrm{C}$ for $48 \mathrm{~h}$ ) and "wet" (samples vacuumed at 40 ${ }^{\circ} \mathrm{C}$ for $48 \mathrm{~h}$ and then vacuum-saturated in deionized water and left in the vacuum under water for $48 \mathrm{~h}$ ) experiments. All the samples were deformed uniaxially until failure at a constant strain rate of $10^{-5} / \mathrm{s}$. Saturated samples were deformed in a water bath. More details about the experimental set-up can be found in Heap et al. (2014b). In a large majority of cases, the failure was unstable and the samples could not be retrieved for post-mortem microstructural analysis. However we managed to stop a few experiments before failure. Petrographic thin sections were prepared from these deformed samples. 


\section{Petrophysical and microstructural attributes of the studied carbonates}

Detailed petrophysical and microstructural analysis over the whole length of the EST205 borehole was recently provided for the stylolite-free limestones by Regnet et al. (2014), see in particular their Fig. 6. We refer the reader to this study for details on the stylolite-free materials and will only focus in this section on the main microstructural attributes of the studied rocks and on the potential petrophysical differences induced by or associated to the presence of stylolites. Previous studies on the same carbonates revealed that the materials studied are composed of more than $97 \%$ calcite with minor percentages of dolomite, quartz and clay (Heap et al., 2014a), also in agreement with Regnet et al. (2014), who reported a composition $>99 \%$ calcite in their samples from the same borehole. The studied limestones have another common attribute: they are all microporous (Heap et al., 2014a; Regnet et al., 2014). Fig. 3a shows as an illustration a SEM micrograph of horizon O1 where the microporosity appears heterogeneously distributed. The larger pores visible in this image have a diameter of about 10-15 $\mu \mathrm{m}$ (Fig. 3b). All the studied carbonates have a high degree of cementation, as illustrated on horizon O3 (Fig. 3c). No pores larger than $5 \mu \mathrm{m}$ could be observed in this layer. X-ray Computed Tomography data (CT) were also acquired at a resolution of 4 microns on a $4 \mathrm{~mm}$ sample from the same depth (Fig. 4). Even at this high resolution, one cannot resolve individual pores and the porosity is typically concentrated around the ooliths (darker zones in the CT image).

\section{Figure 3}

\section{Figure 4}

Considering the low percentages of secondary minerals, it is reasonable to estimate the porosity of the samples using simply their dry mass and considering $100 \%$ calcite (assuming a calcite density of $2.71 \mathrm{~g} / \mathrm{cm}^{3}$ ). Comparison with He pycnometer measurements on a selection of samples showed an agreement between both estimations within less than $5 \%$. This also 
means that the proportion of disconnected porosity, if any exists, is within the error bars of the measurements. For saturated samples, we observed a difference of about $0.01 \%$ (on average) between the porosity determined by triple weight and that determined by the dry mass only. It is likely that water failed to saturate all of the very small pores. However, while this imperfect saturation could be an issue for some petrophysical measurements, Schmitt et al. (1994) showed on various rock types that it has virtually no effect on the brittle strength for saturation as low as $20 \%$.

The porosity of our samples was found in the range 0.6 to 0.21 . Average porosity for the 6 layers is given in Table 1. We observed that sample porosity decreases with depth (Fig. 5). All the samples with a stylolite were found, independent of the orientation, to be more porous than the stylolite-free host rock. The measured difference in porosity was between 0.01 and 0.03. Higher porosities associated with the presence of stylolites were also reported in several previous studies (Dawson, 1988; Braithwaite, 1989; Raynaud and Carrio-Schaffhauser, 1992; Lind et al., 1994; Heap et al., 2014a). This could be related to the formation of the stylolite, in particular if stylolites are seen as the product of the horizontal linkage and vertical coalescence of numerous pressure-solution seams (Nenna and Aydin, 2011), a scenario that promotes the development of secondary porosity. Other interpretation of these higher porosity zones could be the injection of non-equilibrated fluid if stylolites acted as conduits for flow, or more simply the fact that the stylolites grew preferentially in zones of higher porosity, as suggested for the formation of compaction bands (Vajdova et al., 2012).

\section{Figure 5}

We estimated the extent of the larger porosity zone surrounding the stylolites by making porosity measurements at regular intervals $(\sim 0.5-1 \mathrm{~cm})$ on several cylindrical columns of 10 $\mathrm{cm}$ length. A representative example for the horizon $\mathrm{O} 3$ is shown in Fig. 6a. One can see that 
significantly higher porosity was only observed in the immediate surroundings on the stylolite ( $\sim 0.5 \mathrm{~cm})$. This means that for a $4 \mathrm{~cm}$ length sample cored perpendicular to bedding, as shown in Fig. 2, there will be a significant difference in porosity between the central part of the sample and the sample ends. Mercury injection experiments were also performed on a few selected samples taken from the same column (Fig. 6b). Most of the pore-throats have a diameter $<1 \mu \mathrm{m}$. These data also suggest that the average pore-throat diameter increased slightly close to the stylolite.

Rolland (2013) presented some P-wave velocity data and specific area measurements on the same carbonate layers. These data did not reveal any systematic variations in the vicinity of the stylolite. This confirmed our visual and microstructural observations that the higher porosities measured close to the stylolite were not due to microcracking.

Previous studies on stylolites also stressed that they are expected to have a complex internal structure due to the hierarchical nature of their formation, combined with the impact of grainscale heterogeneities (Ebner et al., 2010) and to the inhomogeneous stress distribution surrounding geometric asperities (Zhou and Aydin, 2010). The first order consequence of this complexity is that the stylolite and its surroundings are also more heterogeneous than the host rock.Fig. 7a shows the tortuous path of a stylolite in layer O3. While the stylolites are visible on the sample surface, they are more challenging to follow at smaller scale and in fact it is their complex and heterogeneous nature, with grain partially dissolved (Fig. 7b), that reveals them in optical and SEM micrographs..

\section{Figure 6}

\section{Mechanical data}


We performed 48 uniaxial tests in total, including 32 on samples with a stylolite.

Representative stress-strain curves are presented in Fig. 8. For reasons explained earlier, we had to disregard a fair number of samples and this is why we cannot provide a complete set of dry and wet experiments for all the orientations and all the layers. When we anticipated that testing all the orientations would not be possible, we used the remaining parts of the cores to duplicate certain tests and appreciate the repeatability of the results.

We observed that the Uniaxial Compressive Strength (UCS) of the stylolite-free limestone is in the range 48-150 MPa in dry conditions and 30-90 MPa in wet conditions. The stylolite free material did not show any evidence of mechanical anisotropy, as it can be seen on Fig. $8 \mathrm{f}$ for O3. This is perhaps not unexpected since Rolland (2013) and Heap et al. (2014a) did not measure any anisotropy of P-wave velocity and permeability on the same rocks, respectively.

As far as the impact of stylolites is concerned, the main features that can be seen in Fig. 8 and are the following:

- The stress-strain curves of the samples with a stylolite and the stylolite-free samples did not show any significant differences, and both were typical of what is usually observed in this type of uniaxial experiment: after an elastic (linear) stage, the curves reach a peak beyond which strain softening and unstable failure occur. We note however that the failure appeared more unstable when the stylolite was oriented parallel to the applied stress.

- All the samples with a stylolite are weaker than the corresponding stylolite-free samples.

- The difference in strength between the samples with a stylolite and the stylolite-free samples is about the same in dry and wet conditions. 
- In all tested horizons, the presence of a stylolite did not induce any mechanical anisotropy and the UCS was about the same for samples with a stylolite oriented orthogonal, parallel, or oblique to the direction of the applied stress (vertical).

- In most cases, the tangent modulus of the samples with a stylolite was smaller than that of the stylolite-free samples.

\section{Figure 8}

\section{Failure modes and microstructural observations}

All the stylolite-free samples failed by axial splitting (Fig. 9a). We managed to stop one of the experiments on layer O3, shortly after the peak stress. As expected, we observed axial microcracking distributed homogeneously in the sample and cutting through the cement and the ooids (Fig. 9b). The failure mode was similar for samples with a stylolite oriented orthogonal to the applied stress. Even if our experimental set-up allowed us to observe the sample during deformation, it was not always possible to spot from where the main fracture initiated. Post-mortem observations of these samples showed that the main macroscopic fracture either cuts through the stylolite plane (Fig. 9c), or occurred in two stages where half of the sample is first broken from one end to the stylolite plane, and then the failure continued seconds later from the same position in the stylolite plane or with some horizontal offset as in the example shown in Fig. 9d. We studied the microstructure of one deformed sample of layer O5 that showed less obvious damage. The SEM micrograph of this sample (Fig. 9e) revealed that part of the axial microcracking initiated from the stylolite plane and in particular from the larger teeth of the stylolite. These observations suggest that in this orientation the stylolite plane (and perhaps its surroundings) acted as a zone of high stress concentration and played a fundamental role in the development of stress-induced damage and failure of the sample. 
When the stylolite plane was oriented parallel or oblique with respect to the applied stress, we observed different failure patterns in the different samples. The common attribute was the fact that failure occurred sub-vertically in most samples and some damage was always associated to the stylolite plane. This could be easily verified on the broken samples since the fracture plane appeared dark when it followed on the stylolite plane (cutting through the insoluble layer) and white when the fracture developed outside the stylolite plane. When the stylolite was oriented parallel to the applied stress, visual inspection of the broken samples suggested that the main failure was in all cases strongly influenced by the presence of the stylolite (Fig.10). When the stylolite was very tortuous, macroscopic cracking cut sub-vertically through its larger (horizontal) teeth, as in the example shown in Fig. 10a. When the stylolite was less tortuous, we often observed only a partial overlap between the stylolite and the failure plane (Fig. 10b), probably due to end effects or/and to the presence of heterogeneities in the sample. We also observed in some cases that failure developed quasi simultaneously in and outside the stylolite plane (Fig. 10c). Fig. 10d-e shows SEM micrographs from a sample of $\mathrm{O} 5$ unloaded just after the peak stress. The density of axial microcracks appeared larger in the vicinity of the stylolite. In some cases, sub-vertical microcracks followed the stylolite path (Fig. 10d) and sometimes cut through the larger teeth when the stylolite becomes more tortuous (Fig. 10e).

\section{We had only a few samples with oblique stylolites because their preparation limited} considerably the number of available samples in the other orientations from the same stylolite. In the deformed samples with an oblique stylolite, we observed that macroscopic failure occurred for the most part on the stylolite plane, as in the example shown in Fig. 11a. In this orientation, the failure mode was therefore different from the axial splitting seen in other orientations. However, we also typically observed some axial microcracking emanating from 
the stylolite, creating secondary sub-axial macrofractures (Fig. 11a). SEM microstructural observations made on a sample of deformed O5 just beyond the peak stress confirmed what visual inspection of the samples suggested: when the stylolite is less tortuous, stress-induced damage mostly followed its path (Fig. 11b). However, if when the stylolite was more tortuous, including some sub-horizontal segments, stress induced microcracks were mostly observed in the direction of the applied stress (Fig. 11c).

In summary, in all deformed samples with a stylolite, visual inspection and microstructural observations suggested a major influence of the stylolite on stress-induced damage and failure, consistent with our mechanical data showing that the presence of a stylolite always induced weakening (Figure 8).

\section{Stochastic modelling}

\section{Figure 11}

The analysis of brittle failure is samples containing a stylolite could not be achieved using standard micromechanical modelling (see for example Baud et al., 2014) due to the inherent heterogeneity of these samples (see section 3). One has to therefore rely on numerical modelling for this type of complex problem. In this study, we chose to use the 2D Rock Failure Process Analysis finite element code (RFPA 2 D) developed by Tang (1997) and applied in several previous studies to brittle failure of carbonates (Wong et al., 2006) and, more recently, volcanic rocks (Heap et al., 2014c; 2015). The numerical samples of this study (rectangles $40 \mathrm{~mm}$ in length and $20 \mathrm{~mm}$ in width) consist of 51, 200 square elements (Fig. 12a). Because our carbonates are all microporous, we did not include any macroscopic voids in the numerical samples and assumed that the local strength of the element reflects the presence of micropores. To also reflect material heterogeneity at the element scale, each 
square is assigned Young's modulus and strength using a Weibull probability distribution function (Weibull, 1951):

$$
f(\sigma)=\frac{m}{\sigma_{0}}\left(\frac{\sigma}{\sigma_{0}}\right)^{m-1} \exp \left[-\left(\frac{\sigma}{\sigma_{0}}\right)^{m}\right]
$$

The statistics for failure involve therefore two parameters: $\sigma_{0}$ proportional to the mean of the strength distribution and $m$ which characterizes the degree of heterogeneity of the material. High values of $m$ lead to homogeneous samples, and vice-versa. Linear constitutive laws are considered for each element until failure that can occur in shear and tensile mode. Importantly, when an element fails, it is replaced by the same element with a considerably lower strength and Young's modulus. Further details on the model could be found in Tang (1997), Wong et al. (2006), and Heap et al. (2015).

We decided to apply this approach to our data on the layer O3. The first step was to set the model parameters to match our data on the stylolite-free material. Table 2 presents the parameters used for this simple case and Fig. 13a shows the simulated stress-strain curve together with the data. The evolution of damage in this simple case is also shown in Fig. 13b. It is clear that the set of parameters giving such results is by no means unique but this is of little importance in this study since we primarily focused here on the impact of stylolites.

The second step was to create numerical samples representative of the samples with a stylolite in the different orientations. Guided by our petrophysical data, we first examined the possibility that the observed mechanical behavior and damage patterns would be mostly due to the fact that the thin stylolite is in the middle of a weaker, more porous zone. We therefore performed a first series of simulations with the geometries shown in Fig. 12c-d. The presence of the stylolite in the samples was modelled by a zone of $5 \mathrm{~mm}$ thick, while the rest of the sample has the same properties than the stylolite-free sample. Numerous attempts were made 
using these geometries in which we varied the thickness and properties of the "stylolite zone" to yield results comparable to our mechanical data on O3. Of course, the geometries shown in Fig. 12c-d introduced more parameters in the model, but the situation with a stylolite was also more constrained by measured values of the strength and elastic parameters in three orientations. Our parametric study showed that our uniaxial data on O3 could be reasonably approached if one considers that the strength of the stylolite zone is $10 \%$ less than that of the stylolite-free sample. The parameters for this case, which we will call Simulation 1 from hereon in, are shown in Table 2. The simulated stress-strain curves and damage evolutions are shown in Fig. 14. Damage development in the simulation when the stylolite is either orthogonal or parallel to the applied stress is very similar to our post-mortem observations on deformed samples (Fig. 14b and c). However, we noted two important discrepancies between the results of Simulation 1 and the data. First, the model always predicted a mild mechanical anisotropy (Fig. 14a) with the oblique orientation being always significantly weaker, in contrast to our data. Second, and clearly related to the previous point, failure for the oblique orientation is predicted to occur solely in the stylolite zone with little damage developing in the rest of the sample (Fig. 14d). Additional simulations with the same geometries, considering a more heterogeneous stylolite zone (decreasing $m$ by $25 \%$ ) and the same strength as the stylolite-free material, led to results almost identical to those presented in Fig. 14. The conclusion is that the numerical samples considered in Fig. 12c-d are too simple, and the simulations suggested that the stylolite geometry needed to be considered in the simulations.

To check this, we implemented a second series of simulations (Simulations 2) on the numerical samples shown in Fig. 12e-g. This time, we digitized one of the stylolites observed in a sample with a vertical stylolite and rotated this stylolite for the other orientations. We imposed, as in Simulation 1, that the stylolite had the same properties than the stylolite-free, except that its strength was $25 \%$ less (Table 2). These geometries did not result in any 
mechanical anisotropy and the simulated damage patterns are in qualitative agreement with our observations (Fig. 15 b-d). In particular, the failure mode for the oblique stylolite was significantly different than in Simulation 1, due to the stylolite roughness, and failure occurred this time only partially on the stylolite plane (Fig. 15b). Similarly to Simulation 1, keeping the same strength for the stylolite and making it more heterogeneous results in qualitatively similar results. Obviously a weaker and more heterogeneous stylolite with slightly different parameter combinations would also give similar results.

In summary, our numerical simulations using the $\mathrm{RFPA}_{2 \mathrm{D}}$ code showed that it is possible to produce results in qualitative and quantitative agreement with our mechanical data and observations on samples with a stylolite, by considering the following ingredients in the simulations:

-a stylolite seen as a weaker and/or more heterogeneous zone in a carbonate formation, in agreement with our petrophysical measurements and microstructural observations;

-and a certain roughness of the stylolite, which according to the simulations, is the main factor leading to the absence of mechanical anisotropy.

\section{Discussion}

\subsection{Microstructural control of mechanical strength of the limestone from Bure}

To provide reference data on the stylolite-free material, we characterized the mechanical behavior of the limestone formations of Oxfordian age located on the top of the ANDRA URL in Bure. We present in Fig. 16 our new dry UCS data against porosity for the stylolitefree samples, together with a compilation of data for allochemical and micritic limestones from Zhu et al. (2010). We first noted that the strength of the carbonates from Bure is in most 
cases between the compiled data for the allochemical and micritic limestones. This is not unexpected because, if the rocks from Bure are of allochemical origin, they showed a very high degree of cementation and a very small amount (or a total absence) of macropores, see Fig. 3 and 4 and the previous microstructural results of Heap et al. (2014a) and Regnet et al. (2014). This is in contrast to most allochemical limestones compiled in Fig. 16 (see for example the statistics on macroporosity recently presented in Ji et al., 2012 and 2014). Previous microstructural studies showed that the main micromechanism leading to brittle failure in porous limestone is pore-emanated microcracking (Vajdova et al., 2010; 2012). This scenario was captured by Sammis and Ashby‘s (1986) micromechanical model. In this approach, spherical pores of constant radius are distributed homogeneously in the sample and when loaded beyond a certain stress, microcracks start to develop from the pores, eventually leading to macroscopic failure. Zhu et al. (2010) proposed a polynomial approximation of Sammis and Ashby's (1986) model for the uniaxial compression case which leads to the following simple expression for the UCS:

$$
U C S=\frac{1.325}{\phi^{0.414}} \frac{K_{I C}}{\sqrt{\pi r}}
$$

Where $\phi$ is the porosity, $r$ the pore radius and $K_{I C}$ the toughness of the material. Since the rocks studied here are carbonates, we take $K_{I C} \sim 0.2 \mathrm{MPa} . \mathrm{m}^{1 / 2}$, consistent with the measurementsof Atkinson and Advis (1980). The prediction of Equation (1) for different values of the ratio $K_{I C} / \sqrt{\pi r}$ are presented in Fig. 16 and suggests that the pore-size controlling brittle failure in these rocks is, according to the model, around $15 \mu \mathrm{m}$. This value is high with respect to our microstructural observations and CT data (Figs. 3 and 4). It is possible that the spatial distribution of microporosity primarily at the periphery of the ooids (Fig. 4) had some influence on the strength of the rocks and this is not taken into account in the model. 
394 We observed for all the tested rocks a large water-weakening effect, with in average a

395 reduction of $34 \%$ of the UCS in the water-saturated sample. Brantut et al. (2014) recently 396 showed that significant time-dependent deformation due to stress-corrosion microcracking

397 could occur in limestone in the presence of water. Considering that the experiments were performed at relatively large strain rates, we do not believe that this was a factor here and water-weakening had to be related to some time-independent process. Following Equation 1, it is more likely that this weakening effect is due to a reduction of the fracture surface energy (and consequently of $K_{I C}$ ) in the presence of water as it has been observed in other rocks such as sandstone (Baud et al., 2000) and Tuff (Zhu et al., 2011). Our results suggest that the reduction of the fracture surface energy in the presence of water is more pronounced in limestone than in sandstone. Direct measurements of $K_{I C}$ on dry and wet limestones should be performed to confirm this conclusion. Such work is beyond the scope of this study.

\subsection{Impact of stylolites on strength}

Our new data compiled in Fig. 17 show an average reduction of the UCS of $28 \%$ for a sample containing a stylolite. This reduction was however quite variable and was found to be in the range 10 to $60 \%$. Since the studied stylolites were closed, we can consider these numbers as lower bounds for the expected strength reduction associated with the presence of stylolites. The obvious conclusion is that impact of stylolite on strength of carbonates cannot be neglected in various geophysical and geotechnical applications, even if the stylolites are closed. Our new data also suggests that the origin of this weakening is likely to be complex. Larbi (2003) suggested that stylolites have a weakening effect as they allow the water to penetrate into the rock and dissolve some of the constituents in the stylolites, or cause them to swell. However the results presented in Fig. 8 show a similar reduction in strength for both 
dry and wet samples, ruling out that clay swelling as a factor in our experiments. One unexpected result is the fact that the stylolite orientation had little impact on the strength reduction. One possible explanation would of course be that the stylolites, because they were very thin, did not particularly influence the mechanical behaviour of the sample and that what was observed was only due some petrophysical differences in the vicinity of these structures, either of pre-stylolization origin or in relation to the stylolite nucleation and growth. However, some of our numerical simulations (Simulations 1) showed that it is unlikely to be that simple. Moreover, if we consider that the host rock has a porosity and pore size of $\phi_{\mathrm{h}}$ and $r_{\mathrm{h}}$, and that porosity and pore size around the stylolite is larger: $\phi_{\mathrm{s}}$ and $r_{\mathrm{s}}$, respectively. Assuming for simplicity that the whole sample with a stylolite has these different microstructural attributes, the pore-crack model would predict, assuming that the toughness $K_{I C}$ does not change (Equation 2), a strength reduction $R$ of

$$
R=\frac{U C S^{\mathrm{s}}}{U C S^{\mathrm{h}}}=\left(\frac{\phi_{h}}{\phi_{s}}\right) \sqrt{\frac{r_{h}}{r_{s}}}
$$

With the measured porosity differences, Equation 3 shows that an increase of the pore size by more than a factor 2 would be needed to find $R$ in the measured range. Since only a small volume around the stylolite appeared to have different properties, a higher porosity (Fig. 6a) and a higher pore throat size (Fig. 6b), it is clear that the stylolite as a structure had a major influence on stress-induced damage in the samples. This is essentially what we see in our numerical simulations.

The conclusion is that the strength reduction and failure modes observed in the presence of stylolites are mostly due to the addition of two effects: more porous and therefore weaker material in the vicinity of the stylolite and in the stylolite itself and, the stylolite as a heterogeneity acting as a stress concentrator in the material. Because the roughness of the 
stylolite has as shown an important role in the development of damage, as suggested by our simulations (Fig. 15), this parameter is probably the reason why some scattering was observed in the data, with a few samples being significantly stronger or weaker than others . Spatial variation of the stylolite roughness would indeed promote such variability because some significant difference would then exist between the samples obviously prepared from different parts of the cores. We believe that stochastic modeling was probably the best approach to study this problem because of the inherent differences between the samples.

Additional complexity could also arise from the presence of microcracks around the stylolite. However we believe that such microcracking would mostly enhance the porosity/strength differences between the stylolite and the host rock, which will not significantly change the results presented in Section 6. This was checked through several series of simulations.

\subsection{Stylolites: planes of weakness in carbonate formations?}

The existence of a plane weakness in a rock implies that the rock is weaker in some orientation (Jaeger et al., 2007). Many examples showed that the brittle strength of rocks is strongly influenced by various geological features such as joints and fractures (Bandis et al., 1983; Pollard and Aydin, 1988), and structural heterogeneities such as bedding in sedimentary rocks or cleavage in slates, and preferred orientation and/or arrangement of minerals and cracks in crystalline igneous and metamorphic rocks (Donath, 1964; Vernik et al., 1992; Baud et al., 2005). In most of these cases, a degree of mechanical anisotropy is observed. In a foliated rock such as gneiss, a minimum strength is usually observed when the foliation plane is orientated at $45^{\circ}$ with respect to the major principal stress (Shea and Kronenberg, 1993; Rawling et al., 2002). Similar observations were also reported on shales by Niandou et al. (1997). In crystalline rocks with joints (Jing et al., 1992) anisotropic shear strength was also 
observed. In porous sandstone, significant anisotropy can also be associated with sedimentary bedding. For this case, brittle strength decreases relatively continuously between to endmember situations: the rock deformed perpendicular to bedding giving the maximum strength and the rock deformed parallel to bedding giving the minimum strength (Dunn et al., 1973; Gatelier et al., 2002; Bésuelle et al., 2003; Louis et al., 2009). There is paucity of data on the mechanical anisotropy of the limestone but our new data on the rocks from Bure showed that the stylolite-free material is to the first order isotropic. This is also supported by permeability and P-wave velocity measurements on the same rocks (Rolland, 2013; Heap et al., 2014a).

Our new data on the impact of stylolites appears to contradict field/quarry based observations that exposed stylolites as planes of weakness in carbonate formations. The limited data set of Rashed and Sediek (1997) also suggests that the stylolites induced some anisotropy with minimum strength at some $45^{\circ}$ with respect to the applied stress. The numerical simulations presented in the previous section do not suggest that the presence of microcracks around or in the stylolites would change the observed behavior and explain the differences between our results and field observations. As noted before, this would most probably just introduce more scattering in the results. A likely more important parameter was the observations made during the sample selection out of the cores from EST205 borehole in Bure: thicker stylolites (with thicknesses larger than $1 \mathrm{~cm}$ ) were always associated to macrofracturing in the cores (Fig. 18a) and were therefore impossible to test. Moreover, most attempts made to prepare samples with stylolites of thickness larger than $2-3 \mathrm{~mm}$ resulted in fractures along the stylolite planes during preparation. In the few cases, where the samples did not actually break during preparation, we could always see some macrocracks associated to the stylolite plane (Fig. 18b) and further manipulations of these samples showed that their mechanical strength was dramatically low (Fig. 18c). We therefore believe that the thickness of the stylolites plays a major role on their impact on rock strength. It is important to specify here that the thickness 
that we are referring to is the actual thickness of insoluble elements that can be seen by eye. Taken together, our results therefore suggest the following scenario: when stylolites are thin, as in the studied samples, their roughness plays an important role in the mechanical behavior. Stress concentrations near the larger teeth oriented in the direction of the applied stress promote microcracking in that direction whatever the orientation of the stylolite. This process does not promote the development of mechanical anisotropy as shown in Simulations 2 (section 6) and these stylolites cannot be considered as planes of weakness. However when the stylolite thickness is of the order of several $\mathrm{mm}$ and beyond, what is typically observed is that it becomes less tortuous (Fig. 18a). Then, when loaded, such structure will have the tendency to behave in a similar way than the numerical samples of Simulation 1 and, in turn, stylolites will become obvious planes of weakness and have very low strength when loaded at an angle to their plane.

\section{Figure 18}

\section{Conclusions}

In this study we showed that a significant strength reduction is expected in the presence of stylolites, even if there are thin and closed. Such weakening should be taken into account in geotechnical applications, particularly around the ANDRA URL in Bure, an area where stylolites are abundant in the carbonate formations. Since pressure solution seams and stylolites are not always developed enough to be identified in carbonate rocks, they also could contribute to the scattering in the petrophysical and mechanical data often reported in this rock type (see for example Dautriat et al., 2011).

When the stylolites are thin, we showed that the observed weakening is about the same for a dry or a wet rock, and also appeared to be the same for different orientations of the stylolite 
with respect to the applied stress. Most of the observed strength reduction could be explained by the presence of a higher porosity zone in the vicinity of the stylolite. The stylolite itself plays the role of stress concentrator that influences the development of stress-induced damage and failure mode in the limestone.

Together with systematic observations made on the available cores taken from the Bure site, our new data suggests that stylolites would become planes weakness in carbonate formations beyond a certain thickness. Our observations suggest that this thickness is around $5 \mathrm{~mm}$ and that a more dramatic weakening is to be expected when the stylolite reaches this thickness. Mechanical tests on such thick stylolites were not possible in this study and we believe that they would be extremely challenging to perform. It is in our view more realistic to envisage some indirect in situ measurements to quantify strength for thick stylolites and their impact at various scales.

\section{Acknowledgements}

Data will be available on demand. This work was partially funded by ANDRA through a Ph.D grant for Alexandra Rolland. We thank Bertrand Renaudier and Jean-Daniel Bernard for their very delicate work on the sample preparation. We have benefitted from discussions with Philippe Landrin, François Renard and Teng-fong Wong. We thank Gilles Morvan for his assistance on the SEM.

\section{References}

André, G., 2003. Caractérisation des déformations méso-cénozoïques et des circulations de fluides dans l'Est du Bassin de Paris, thesis, Univ. Henri Poincaré, Nancy, France. 
Atkinson, B.K., Advis, V., 1980. Fracture mechanics parameters of some rock-forming minerals determined using an indentation technique. Int. J. Rock Mech. Min. Sci. \& Geomech. Abst., 17, 383-386.

Bandis, S.C., Lumsden, A.C., Barton, N.R., 1983. Fundamentals of rock joint deformation, Int. J. Rock Mech. Min. Sci., 20(6), 249-268.

Baron, M., Parnell, J., 2007. Relationships between stylolites and cementation in sandstone reservoirs: Examples from the North Sea, U.K. and East Greenland. Sed. Geol., 194(1-2), 1735.

Bathurst R.G.C., 1971. Carbonate sediments and their diagenesis. Amsterdam/London/New York: Elsevier.

Baud, P., Wong, T.-f., Zhu, 2014. Effects of Porosity and Crack Density on Compressive Strength of Rocks, Int. J. Rock Mech. Min. Sci., 67, 202-211, 2014.

Baud, P., Louis, L., David, C., Rawlings, G.C., Wong T.-f., 2005. Effects of bedding and foliation on mechanical anisotropy, damage evolution and failure mode, Geophys. Soc. London Spec. Pub., 245, 223-249.

Baud, P., Zhu, W., Wong, T.-f., 2000. Failure mode and weakening effect of water on sandstone, J. Geophys. Res., 105, 16371-16390.

Bésuelle, P., Baud, P., Wong, T.-f., 2003. Failure mode and spatial distribution of damage in Rothbach sandstone in the brittle-ductile transition. Pure Appl. Geophys. 160, 851-868.

Brantut, N., Heap, M.J., Baud, P., Meredith, P.G., 2014, Mechanisms of time-dependent deformation in porous limestone, J. Geophys. Res., 119(7), 5444-5463. 
559

560

561

562

563

564

565

566

567

568

569

570

571

572

573

574

575

576

577

578

579

Croizé, D., Renard, F., Gratier, J.-P., 2013. Chapter 3- Compaction and porosity reduction in carbonates: A review of observations, theory and experiments, Advances in Geophysics, 54, $181-238$.

Dautriat, J., Gland, N., Dimanov, A., Raphanel, J., 2011. Hydromechanical behavior of heterogeneous carbonate rock under proportional triaxial loading, J; Geophys. Res., 116, doi:10.1029/2009JB000830.

Donath, F.A., 1964. Strength variation and deformational behaviour in anisotropic rock, in State of Stress in the Earth's Crust, edited by W. R Judd, pp. 281-297, New York: American Elsevier.

Dunn, D.E., LaFountain, L.J., Jackson, R.E., 1973. Porosity dependence and mechanism of brittle fracture in sandstones. J. Geophys. Res., 78, 2403-2417.

Dunnington, H. V., 1967. Aspects of diagenesis and shape change in stylolitic limestone reservoirs, Proc. World Pet. Congr. 7th, Mexico, 2, 339-352.

Ebner, M., Piazolo, S., Renard, F., Koehn, D., 2010, Stylolite interfaces and surrounding matrix material: Nature and role of heterogeneities in roughness and microstructural development. J. Struct. Geol., 32(8), 1070-1084.

Gatelier, N., Pellet, F., Loret, B., 2002. Mechanical damage of an anisotropic porous rock in cyclic triaxial tests. Int. J. Rock Mech. Min. Sci., 39, 335-354.

Heald, M.T., 1955. Stylolites in Sandstones. J. Geol., 63(2), 101-114.

Heap, M.J., Baud, P., Reuschlé, T., Meredith, P.G., 2014a. Stylolites in limestones: Barriers to fluid flow?, Geology, 42 (1), 51-54. 
Heap, M., Petrakova, L., Lavallée, Y., Baud, P., Varley N.R., and Dingwell, D.B., 2014b, Microstructural controls on the physical and mechanical properties of edifice-forming andesites at Volcan de Colima, Mexico, J. Geophys. Res., 119, doi:10.1002/2013JB010521.

Heap, M.J., Xu, T., Chen, C-f., 2014c. The influence of porosity and vesicle size on the brittle strength of volcanic rocks and magma, Bull. Volcano., 78:856.

Heap, M. J., T. Xu, A. R. L. Kushnir, B. Kennedy, and C.-f. Chen, 2015. Fracture of magma containing overpressurised pores. Journal of Volcanology and Geothermal Research, 301, 180-190.

Jaeger, J.C., Cook, N.G.W., Zimmerman, R.W., 2007. Fundamentals of Rock Mechanics, 4th ed., 475 pp., Blackwell, Oxford.

Ji, Y., Baud, P., Vajdova, V., Wong, T.-f., 2012. Characterization of pore geometry of Indiana limestone in relation to mechanical compaction, Oil \& Gas Science and Technology - Revue de l'Institut Français du Pétrole, DOI: 10.2516/ogst/2012051.

Jiang, Q., Feng, X-t., Hatzor, Y. H., Hao, X-j., and Li, S.-j., 2014. Mechanical anisotropy of columnar jointed basalts: an example from the Baihetan hydropower station, China, Eng. Geol., 175, 35-45.

Jing, L., Nordlund, E., Stephansson, O., 1992. An experimental study on the anisotropy and stress-dependency of the strength and deformability of rock joints, Int. J. Rock Mech. Min. Sci. Geomech. Abstr., 29, 535-542.

Larbi, J.A., 2003, Effect of stylolites on the durability of building stones: two cases studies, HERON, 48 (3). 
Lind, I., Nykjaer, O., Priisholm, S., Olie, M., Springer, N., 1994. Permeability of stylolitebearing chalk, J. Petrol. Tech., 46, 986-993.

López-Buendía, A.M., Guillem, C., Cuevas, J.M., Mateos, F., Montoto, M., 2013. Natural stone reinforcement of discontinuities with resin for industrial processing, Eng. Geol., 166, $39-51$.

Louis, L., Baud, P., Wong, T.-f., 2009. Microstructural inhomogeneity and mechanical anisotropy associated with bedding in sandstone, Pure Appl. Geophys., 166, 1063-1087.

Nelson, R.A., 1981. Significance of fracture sets associated with stylolite zones, Am. Assoc. Petrol. Geol. Bull., 65, 2417-2425.

Nenna, F.A., Aydin, A., 2011. The formation and growth of pressure solution seams in clastic rocks: A field and analytical study, J. Struct. Geol., 33, 633-643.

Niandou, H., Shao, J.F., Henry, J.P., Fourmaintraux, D., 1997. Laboratory investigation of the mechanical behaviour of Tournemire shale. Int. J. Rock Mech. Min. Sci., 34, 3-16.

Nicholson, D.T., and Nicholson, F.H., 2000. Physical deterioration of sedimentary rocks subjected to freeze -thaw weathering, Earth Surf. Proc. Land., 25 (12), 1295-1307.

Özvan, A., Dincer, I., Acar, A., 2011. Quality Assessment of Geo-materials for coastal structures (Yumurtalik, Turkey), Marine Geores. Tech., 29, 299-316.

Park, W.C., Schot, E. H., 1968. Stylolites: their nature and origin. J. Sed. Petrol., 38(1), 175191.

Pires, V., Silva, Z.S., G, Simão, J.A.R., Galhano, C., Amaral, P.M., 2010. "Bianco di Asiago" limestone pavement - Degradation and alteration study, Construt. Build. Mat., 24, 686-694. 
Pollard, D.D., Aydin, A.A., 1988, Progress in understanding jointing over the past century: Geological Society of America Bulletin, v. 100, p. 1181-1204

Rashed, M.A., Sediek, K.N., 1997. Petrography, diagenesis and geotechnical properties of the El-Rufuf Formation (Thebes Group), El-Kharga Oasis, Egypt, J. Afr. Earth Sc., 25 (3), $407-$ 423.

Rawling, G.C, Baud, P., Wong, T.-f., 2002. Dilatancy, brittle strength, and anisotropy of foliated rocks: Experimental deformation and micromechanical modeling, J. Geophys. Res., 107 (10), 1-14, 2002.

Regnet, J.B., Robion, P., David, C., Fortin, J., Brigaud, B., Yven, B., 2015. Acoustic and reservoir properties of microporous carbonate rocks: implication of micrite particle size and morphology, J. Geophys. Res., doi:10.1002/2014JB011313.

Rolland, A., Toussaint, R., Baud, P., Conil, N., Landrein, P., 2014. Morphological analysis of sedimentary stylolites for paleostress estimation in limestones surrounding the Andra Underground Research Laboratory site, Int. J. Rock Mech. Min. Sci., 67, 212-225.

Rolland, A., 2013. Rhéologie, localisation de la déformation et histoire des contraintes dans les calcaires du site de Bure, Thèse de doctorat, Université de Strasbourg.

Rolland, A., Toussaint, R., Baud, P., Schmittbuhl, J., Conil, N., Koehn, D., Renard, F., Gratier, J.-P., 2012. Modeling the growth of stylolites in sedimentary rocks, J. Geophys. Res., Volume 117 (6), B06403.

Rustichelli, A., Tondi, E., Korneva, I., Baud, P., Vinciguerra, S., Agosta, F., Reuschlé, T., Janiseck, J.M., 201. Bedding parallel stylolites in shallow-water limestone successions of the Apulian Carbonate Platform (central-southern Italy), Italian J. Geos., in press. 
644

645

646

647

648

649

650

651

652

653

654

655

656

657

658

659

660

661

662

663

664

665

Rutter, E.H., 1983. Pressure solution in nature, theory and experiment, J Geol. Soc., 140, 725740.

Sammis, C.G., Ashby, M.F., 1986. The failure of brittle porous solids under compressive stress states. Acta metall. 34, 511-526.

Schmitt, L., Forsans T., Santarelli, F.J., 1994. Shale testing and capillary phenomena, Int. J.

Rock Mech. Min. Sci. \& Geomech. Abstr., Vol. 31, No. 5, 411-427.

Shea, W.T., Kronenberg, A.T, 1993. Strength and anisotropy of foliated rocks with varied mica contents, J. Struct. Geol., 15, 1097-112.

Schmittbuhl, J., Renard, F., Gratier, J.P., Toussaint, R., 2004. Roughness of stylolites:

Implications of 3D high resolution topography measurements, Phys. Rev. Lett. 93 (23), 238501, doi:10.1103/PhysRevLett.93.238501.

Schultz, R.A., 1995. Limits on strength and deformation properties of jointed basaltic rock masses, Rock Mech. Rock Eng., 28(1), 1-15.

Stockdale, P.B., 1943, Stylolites: primary or secondary?, J. Sediment. Petrol. 13, 3-12.

Vajdova, V., Baud, P., Wu, L., Wong, T.-f., 2012. Micromechanics of inelastic compaction in two allochemical limestones, J. Struct. Geol., 43, 100-117.

Vajdova, V., Zhu, W., Chen T.-M.N., Wong, T.-f., 2010. Micromechanics of brittle faulting and cataclastic flow in Tavel limestone, J. Struct. Geol., 32, 1158-1169.

Vernik, L., Lockner, D., Zoback, M.D., 1992. Anisotropic strength of some typical metamorphic rocks from the KTB pilot hole, Germany. Sci. Drill. 3, 153-160.

Tang, C., 1997. Numerical simulation of progressive rock failure and associated seismicity, Int. J. Rock Mech. Min. Sci., 34, 249-261. 
666

667

668

669

670

671

672

673

674

675

676

677

678

679

680

681

682

683

684

685

686

687

Wong, T.-f., Wong, R.H.C., Chau, K.T., Tang, C.A., 2006. Microcrack statistics, Weibull distribution and micromechanical modeling of compressive failure in rock, Mech. Mat., 38,664-681.

Yates, T.J.S., Chakrabarti, B., 1998. Stone Cladding panels: In-Sity Weathering, CRC Press, 1998.

Zhou, X., Aydin, A., 2010. Mechanics of pressure solution seam growth and evolution. J. Geophys. Res.-Solid Earth 115, 18.

Zhu, W., Baud, P., Vinciguerra, S., Wong, T.-f., 2011. Micromechanics of brittle faulting and cataclastic flow in Alban Hills Tuff, J. Geophys. Res., 106, DOI: 10.1029/2010JB008046.

Zhu, W., Baud, P., Wong, T.-f., 2010. Micromechanics of cataclastic pore collapse in limestone, J. Geophys. Res., 115, B04405, doi:10.1029/2009JB006610.

\section{Figure captions}

Fig. 1. (A) Photograph of a section of a core from the borehole EST205 from the ANDRA site in Bure, France. Three stylolites are visible on the core of $\sim 50 \mathrm{~cm}$ length. High resolution photographs showing the details of a stylolite in layers $\mathrm{X}(\mathrm{B})$ and $\mathrm{Y}(\mathrm{C})$

Fig. 2. Preparation of the samples with a stylolite. (A) Slices of about $10 \mathrm{~cm}$ were cut in the cores such as the stylolite is in the middle. (B) We cored in several orientations in this slice (B) to obtain samples with horizontal, vertical and oblique stylolite (C).

Fig. 3. SEM micrographs showing the microporous nature of the carbonates from Bure: (A) microporosity (A) and maximum pore size $\sim 10 \mu \mathrm{m}(\mathrm{B})$ in an intact sample of layer $\mathrm{O} 1$. Highly cemented structure (C) and smaller pore size (D) in in an intact sample of layer O3. 
Fig. 4. Micro CT data with resolution $4 \mu \mathrm{m}$ data on an intact sample of the layer O3. No macropore is visible and the microporosity appears larger near the edge of the allochems (dark areas).

Fig. 5. Porosity stylolite-free samples (red) and samples with a stylolite of carbonates from Bure as a function of depth.

Fig. 6. (A) Evolution of the porosity of the layer O3 near a stylolite. (B) Mercury injection data for the samples 5 (blue), 9 (red) and 11(green) of the same column: Differential intrusion as a function of pore-throat diameter.

Fig. 7. (A) Mosaic of optical micrographs showing a stylolite. (B) Mosaic of SEM micrograph showing the details of stylolite in layer O3.

Fig. 8. Representative mechanical data for uniaxial compression tests performed on carbonates from Bure. Axial stress is presented as a function of axial strain for experiments performed on stylolite free samples (plain lines) and samples with a stylolite (dashed lines). Samples cored orthogonal (Z), parallel (X) and oblique to bedding are presented in blue, red and green, respectively. For samples with a stylolite, triangles indicate the orientation of the stylolite. Dry data are presented on layers O1 (A), O6 (B), O2 (C), O3 (E), O5 (G) and wet data on layers $\mathrm{O} 1(\mathrm{~B}), \mathrm{O} 2(\mathrm{D}), \mathrm{O} 3(\mathrm{~F})$, and $\mathrm{O} 5(\mathrm{H})$.

Fig. 9. (A) Photograph of a stylolite-free sample of layer O3 deformed uniaxially under nominally dry conditions and which failed by axial splitting. (B) SEM micrograph of a sample of layer $\mathrm{O} 3$ deformed uniaxially just beyond the peak stress: axial microcracks cut through the cement and the allochems. Photographs of deformed samples with a horizontal stylolite (orientation $\mathrm{Z}$ ): (C) from the layer $\mathrm{O} 5$ with axial microcracking cutting through the stylolite and (D) from layer O3 showing a more complex failure mode. (E) SEM micrograph of a 
sample from layer $\mathrm{O} 5$ deformed to the peak stress showing that microcracking initiated from the larger teeth of the stylolite. Uniaxial stress was applied in the vertical direction.

Fig. 10. Photographs of deformed samples with vertical stylolite (orientation X) from layers O3 (A-B) and O5 (C). SEM micrographs of sample of O5 deformed just beyond the peak stress: (D) axial microcracking following the stylolite, (E) axial microcracking close to the stylolite in a more tortuous zone. Uniaxial tress was applied in the vertical direction.

Fig. 11. (A) Photograph of a deformed sample of $\mathrm{O} 3$ with an oblique stylolite. Failure occurred both in and out of the stylolite plane. SEM micrographs of a sample of O5 with an oblique stylolite deformed just beyond the peak stress: (B) Microcracking following the stylolite, (C) Sub-axial microcracking initiating from a sub-horizontal part of the stylolite. Uniaxial tress was applied in the vertical direction.

Fig. 12. Numerical samples used in the simulations performed with the RPFA code of (Tang, 1997). (A) stylolite free samples, (B-D) samples used for Simulation 1 with a weaker stylolite zone, (E-F) samples used for Simulation 2 with a thin tortuous and weaker stylolite.

Fig. 13. Results of the simulation for the stylolite free material. (A) Stress as a function of axial strain for the sample $\mathrm{O} 3 \mathrm{i}$ of layer $\mathrm{O} 3$ and for the numerical simulations. The parameters used in the model are listed in Table 2. (B) Stress-induced damage in the numerical sample. Failure of elements appears red when in tension and black when in shear.

Fig. 14. Results of the Simulations 1 for a sample with a stylolite (Fig.11B-D) (A) Stress as a function of axial strain as predicted by the simulations with a $10 \%$ weaker stylolite zone. The parameters used in the model are listed in Table 2. Stress-induced damage in the numerical samples with stylolite oriented orthogonal (B), oblique (C) and (D) parallel to the applied stress (vertical). 
Fig. 15. Results of the Simulations 2 for a sample with a rough stylolite (see Fig. 12 E-F). (A) Stress as a function of axial strain as predicted by the simulations with a $10 \%$ weaker stylolite. The parameters used in the model are listed in Table 2. Stress-induced damage in the numerical samples with stylolite oriented orthogonal (B), oblique (C) and (D) parallel to the applied stress (vertical).

Fig. 16. Comparison of theoretical predictions with laboratory data on unconfined compressive strength (UCS) of micritic (triangles)and allochemical (squares) limestones compiled by Zhu et al. (2010) and the carbonates from Bure (red circles). Theoretical curves of UCS as a function of porosity for four different values of $K_{I C} / \sqrt{\pi r}$ are plotted.

Fig. 17. Compilation of UCS data on samples with a stylolite (plain symbols) and stylolitefree (open symbols): (A) nominally dry samples, (B) water saturated samples.

Fig. 18. (A) Photograph of a core from Bure $(10 \mathrm{~cm}$ diameter). Fracture of this core occurred along a thick stylolite. (B) Photograph of a sample $(4 \mathrm{~cm} \times 2 \mathrm{~cm})$ prepared in a zone with a thick tortuous stylolite. Preparation induced cracking is visible in part of the stylolite plane. This Microcracking made this sample way weaker and it broke mostly on the stylolite plane (C). 


\section{B)}

A)
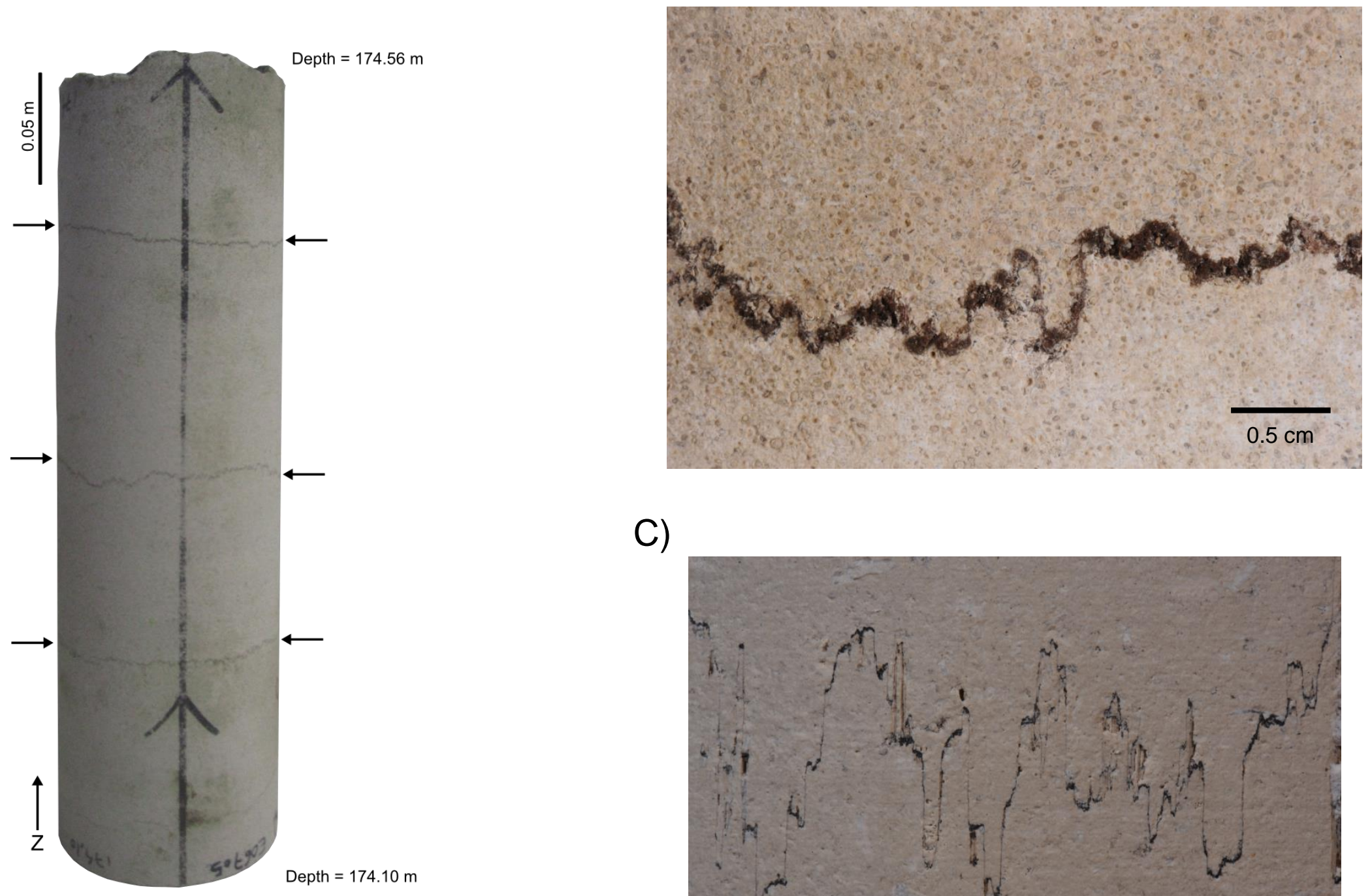

C)

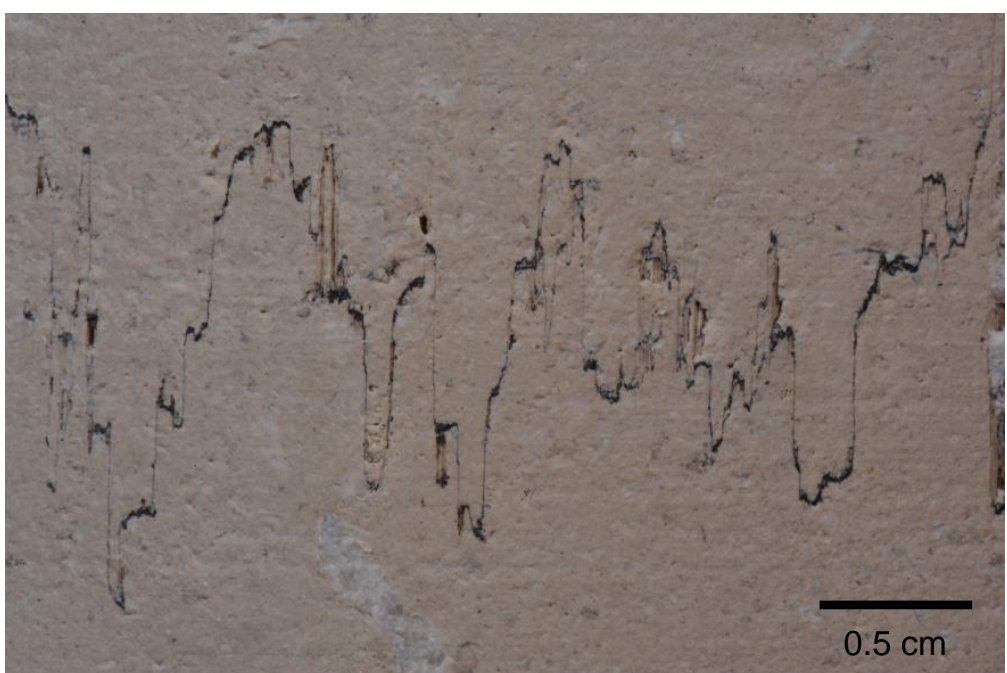

Figure 1 
A)

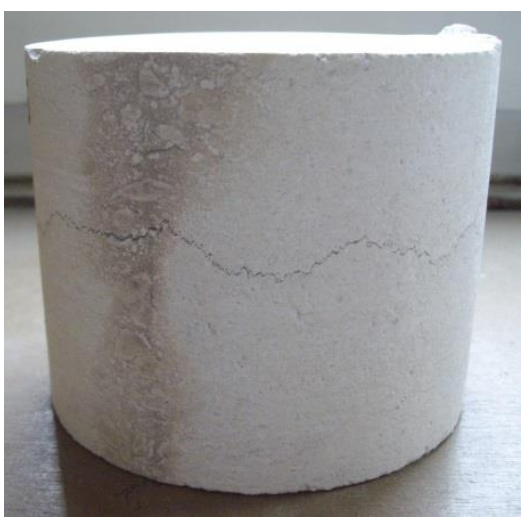

C)

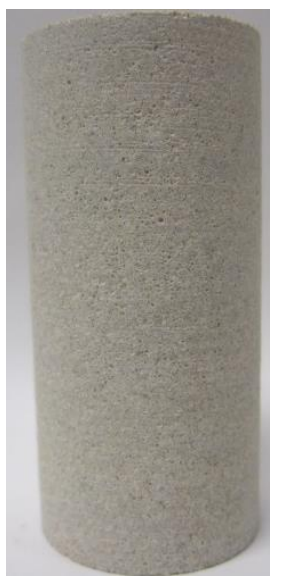

B)
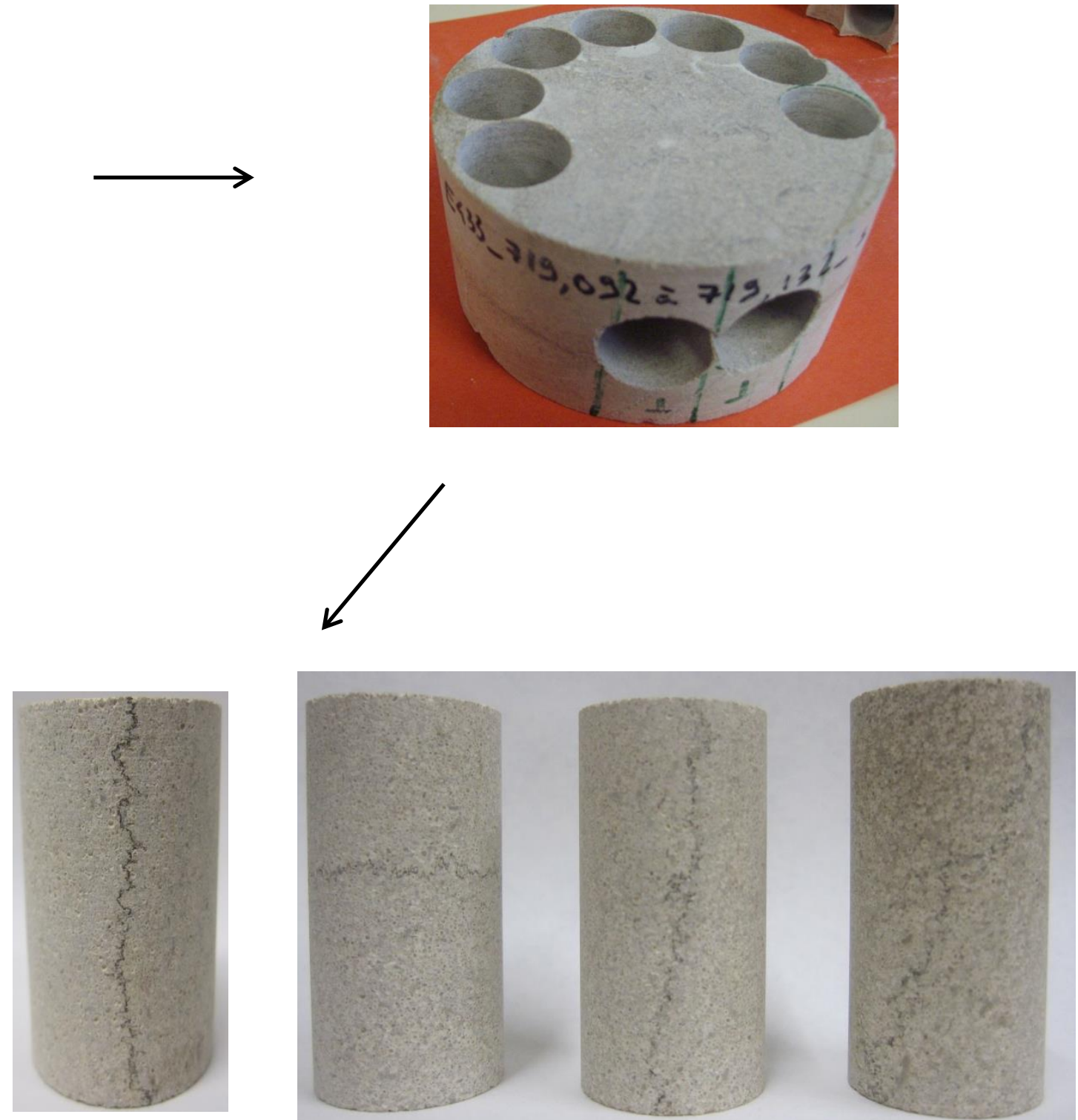

Figure 2 


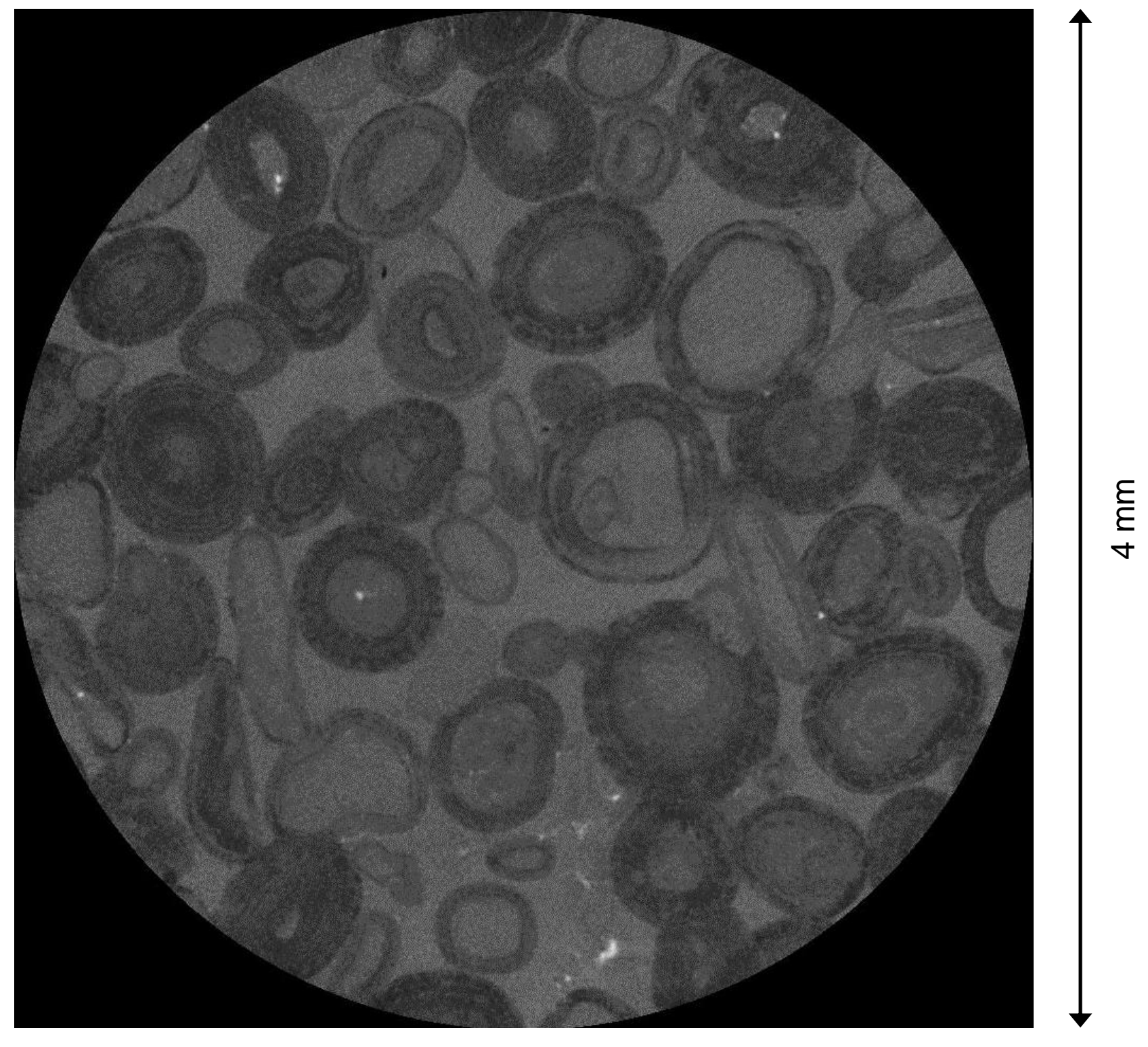

Figure 4 


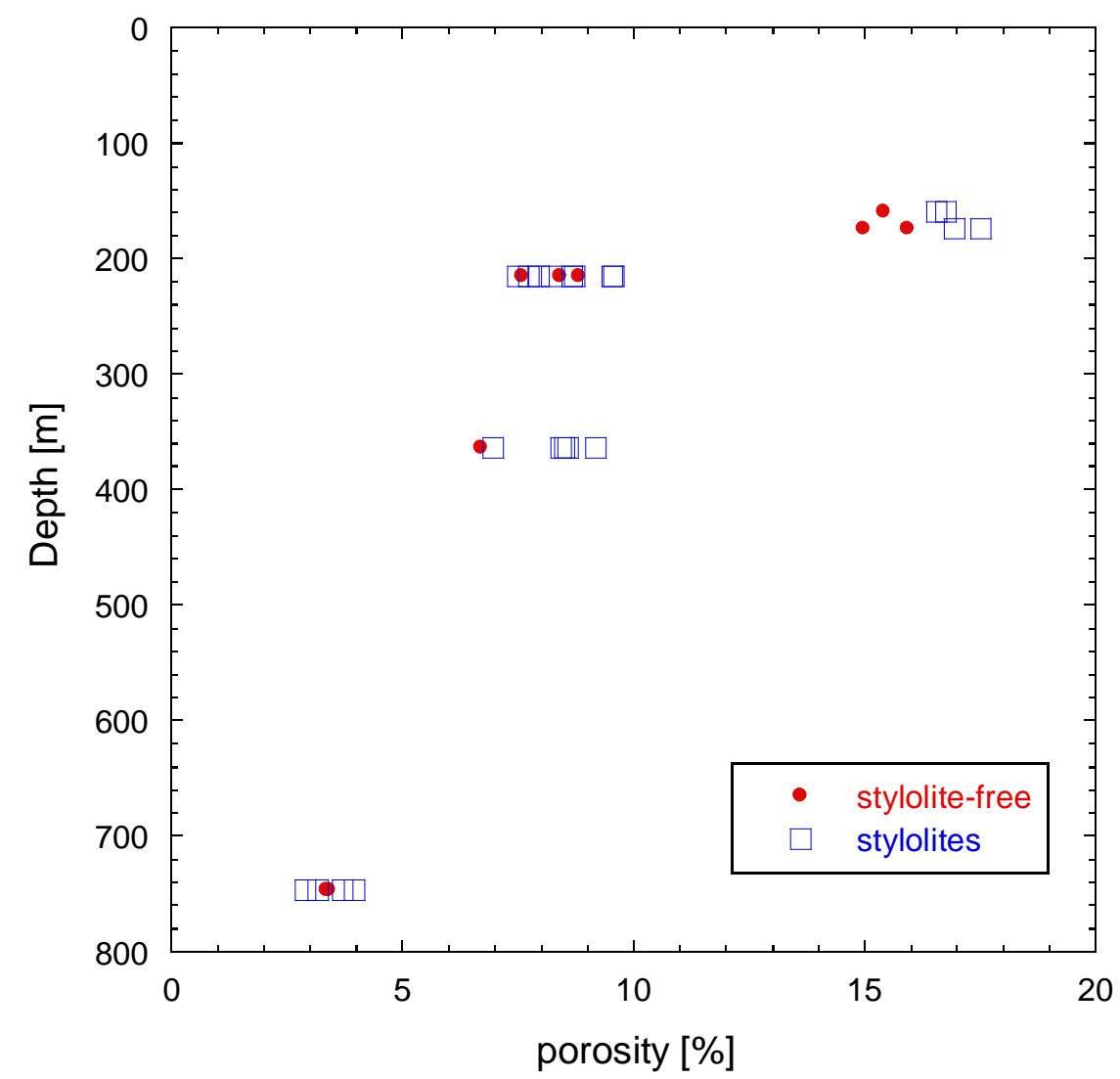

Figure 5 
A)

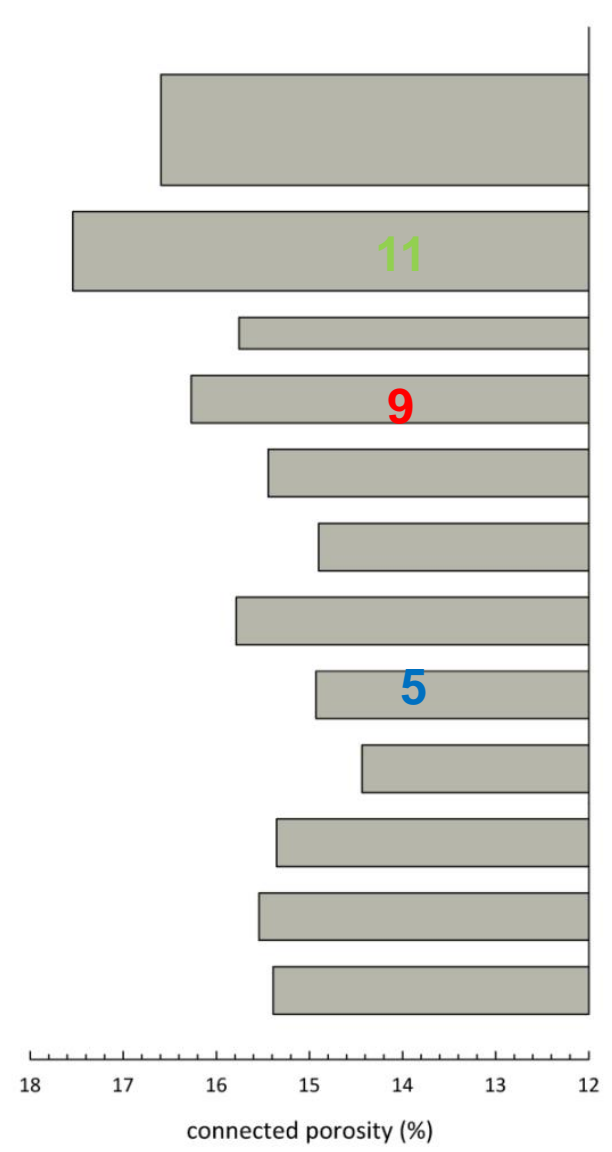

B)

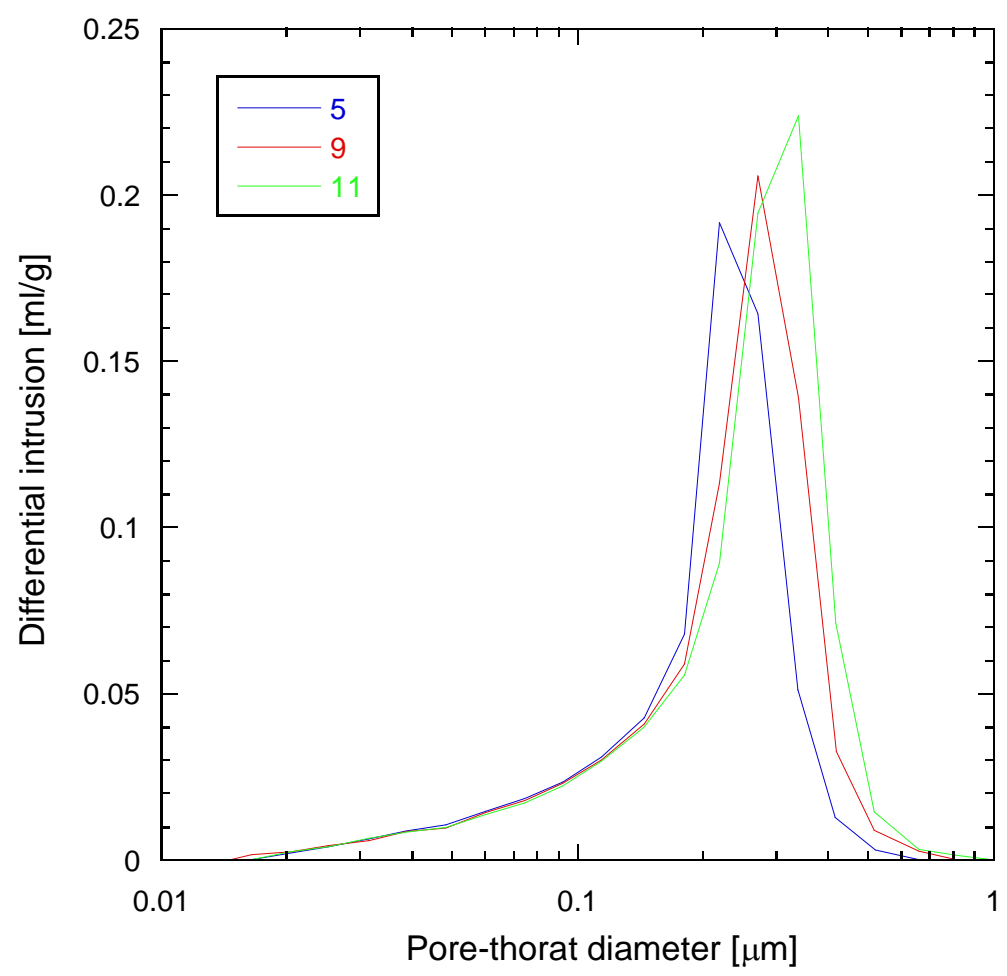

Figure 6 


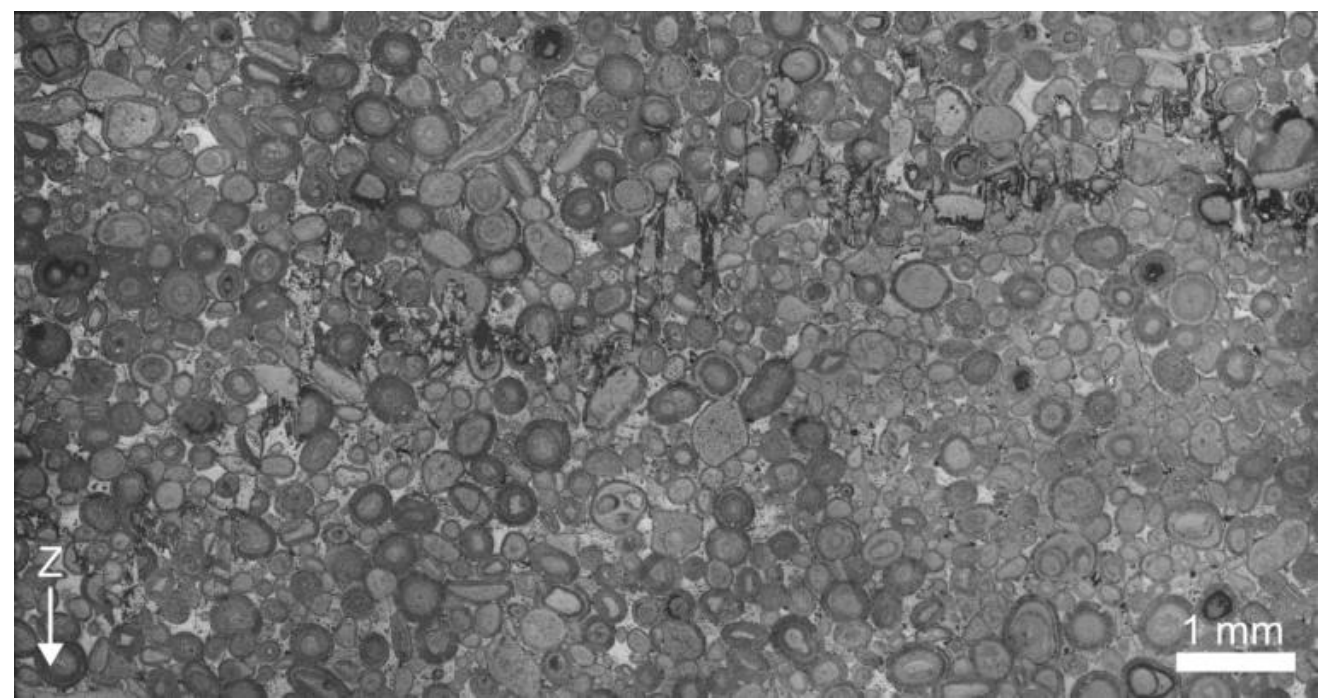

B)

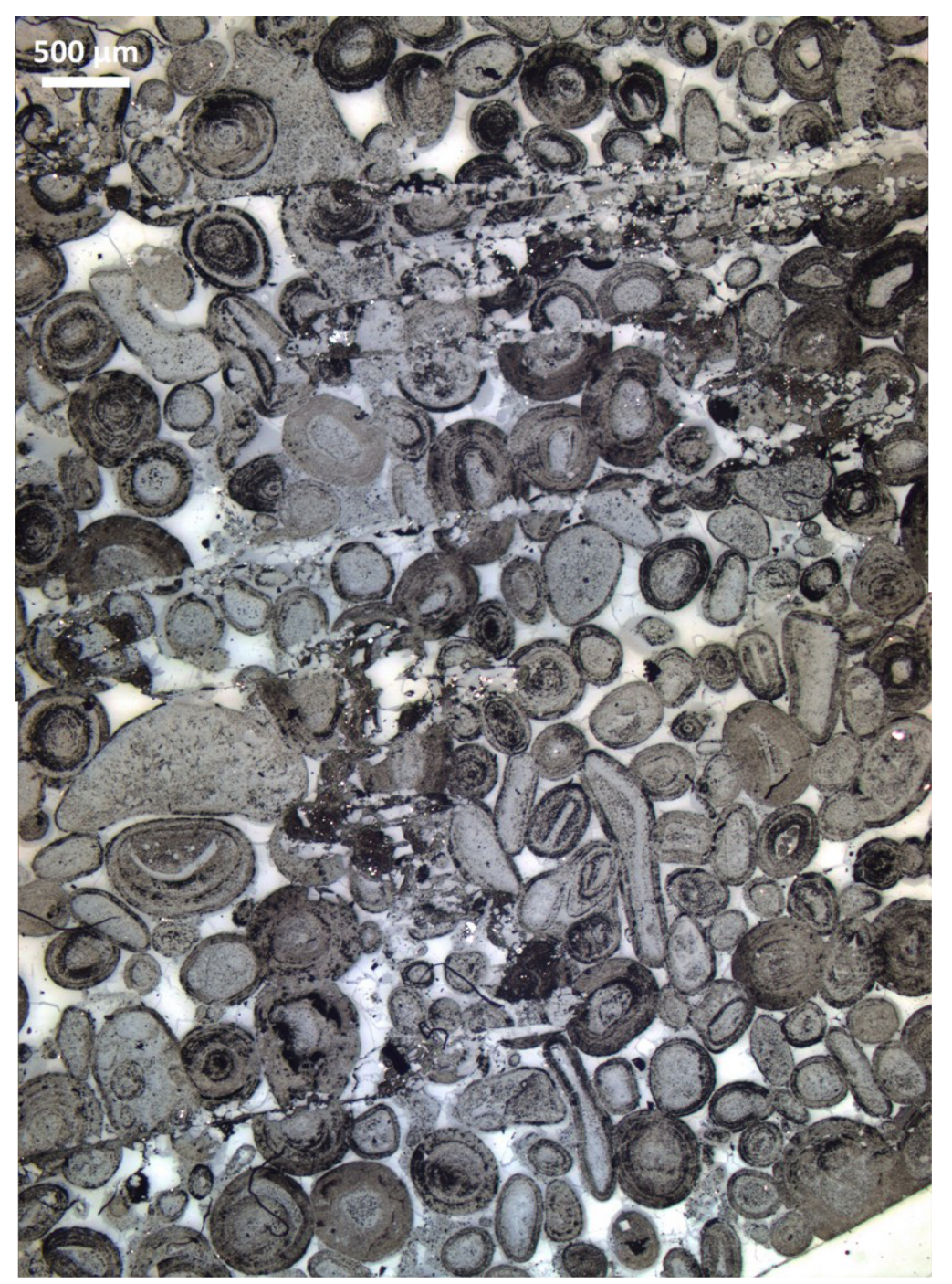

Figure 7 
A)

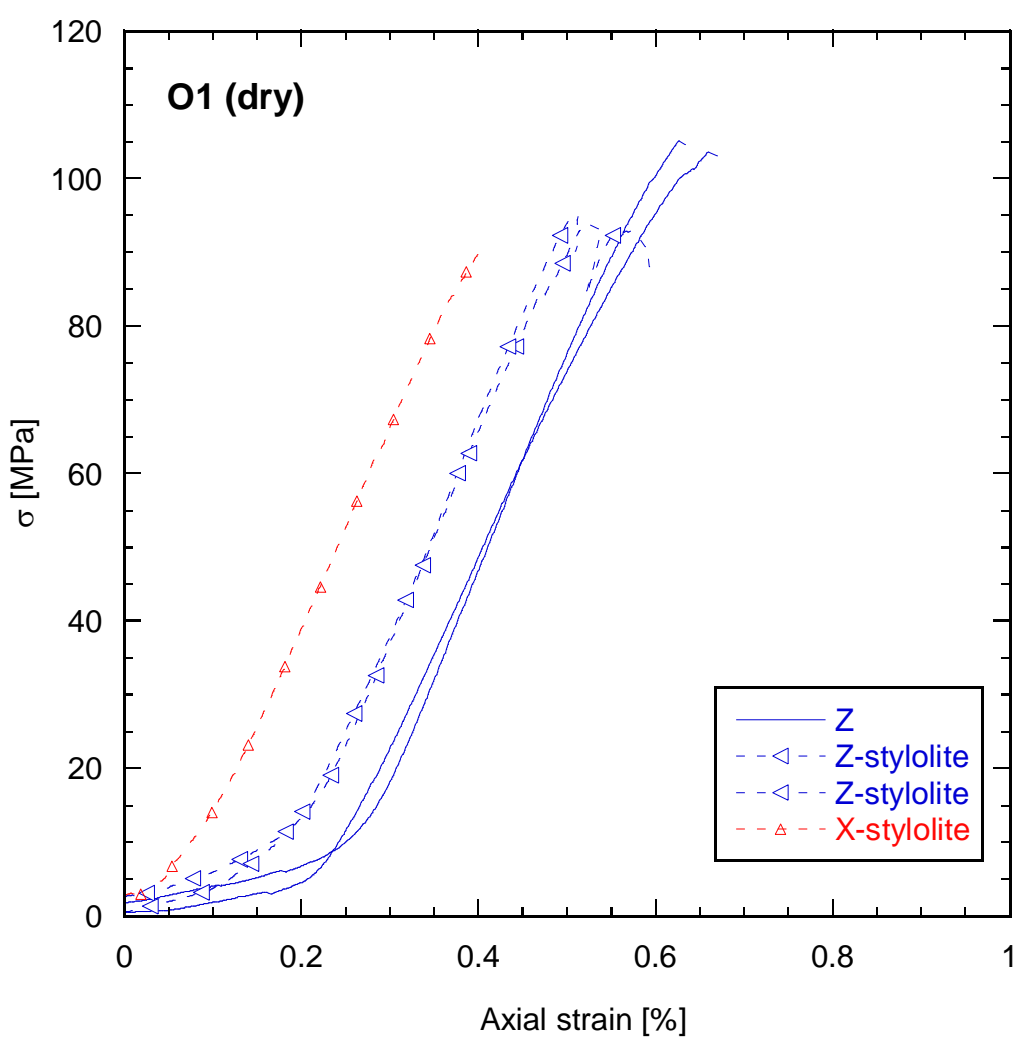

B)

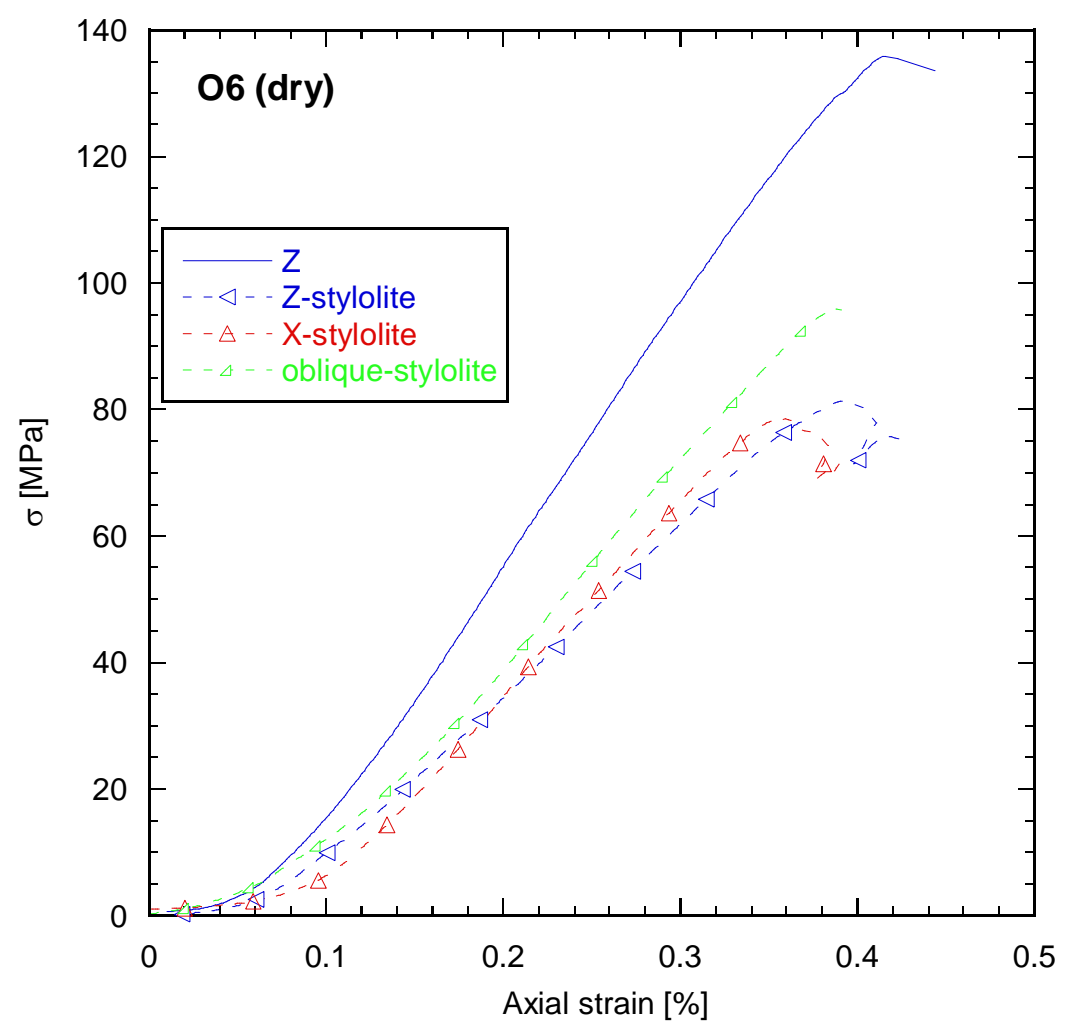

Figure 8 
C)

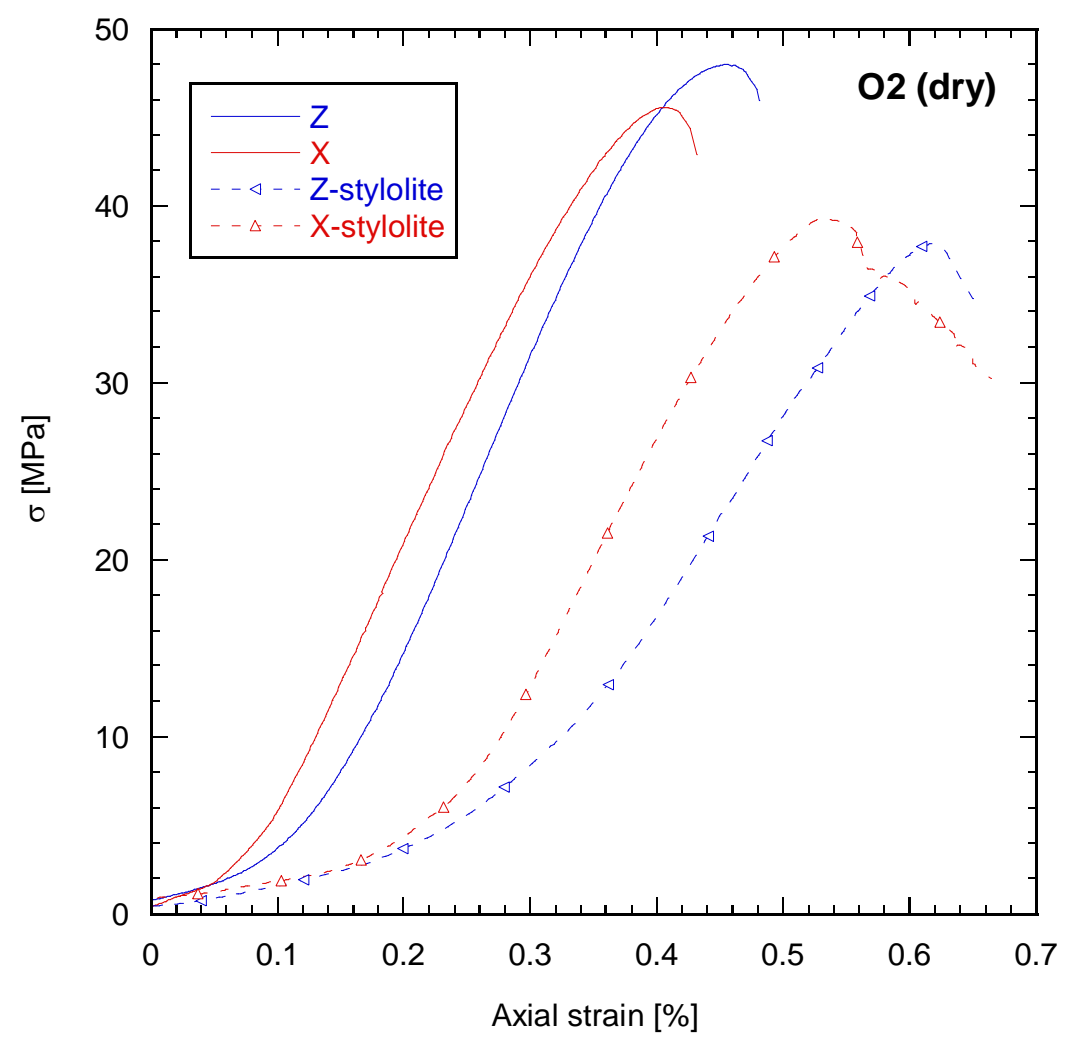

D)

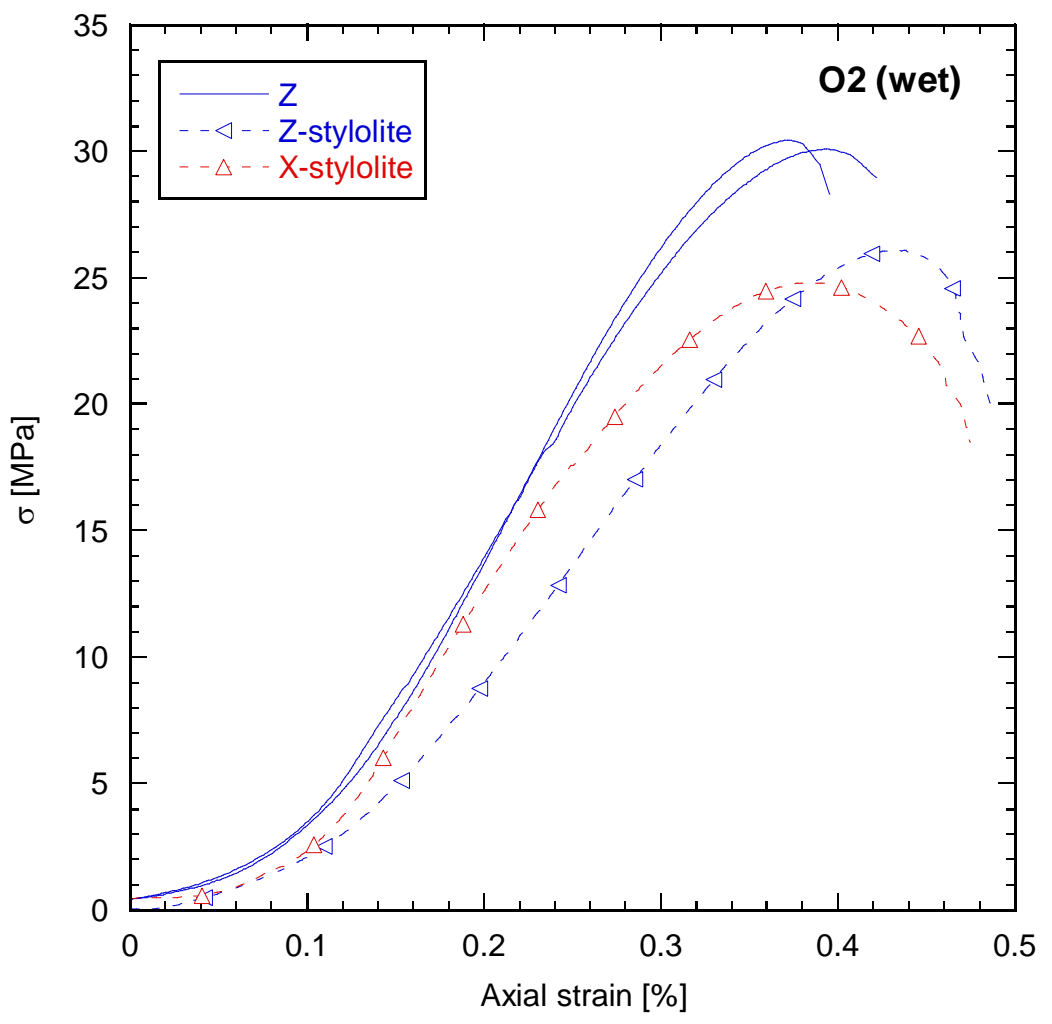


E)

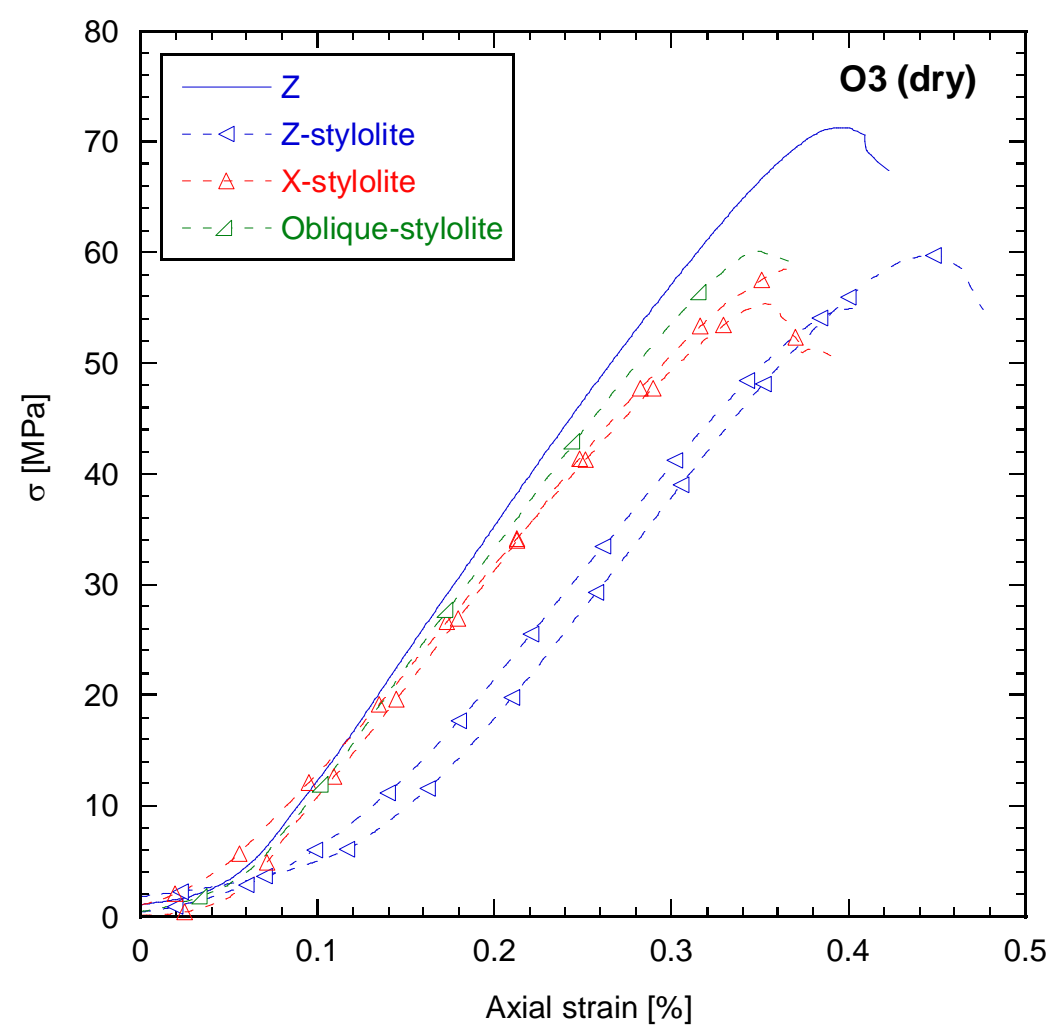

F)

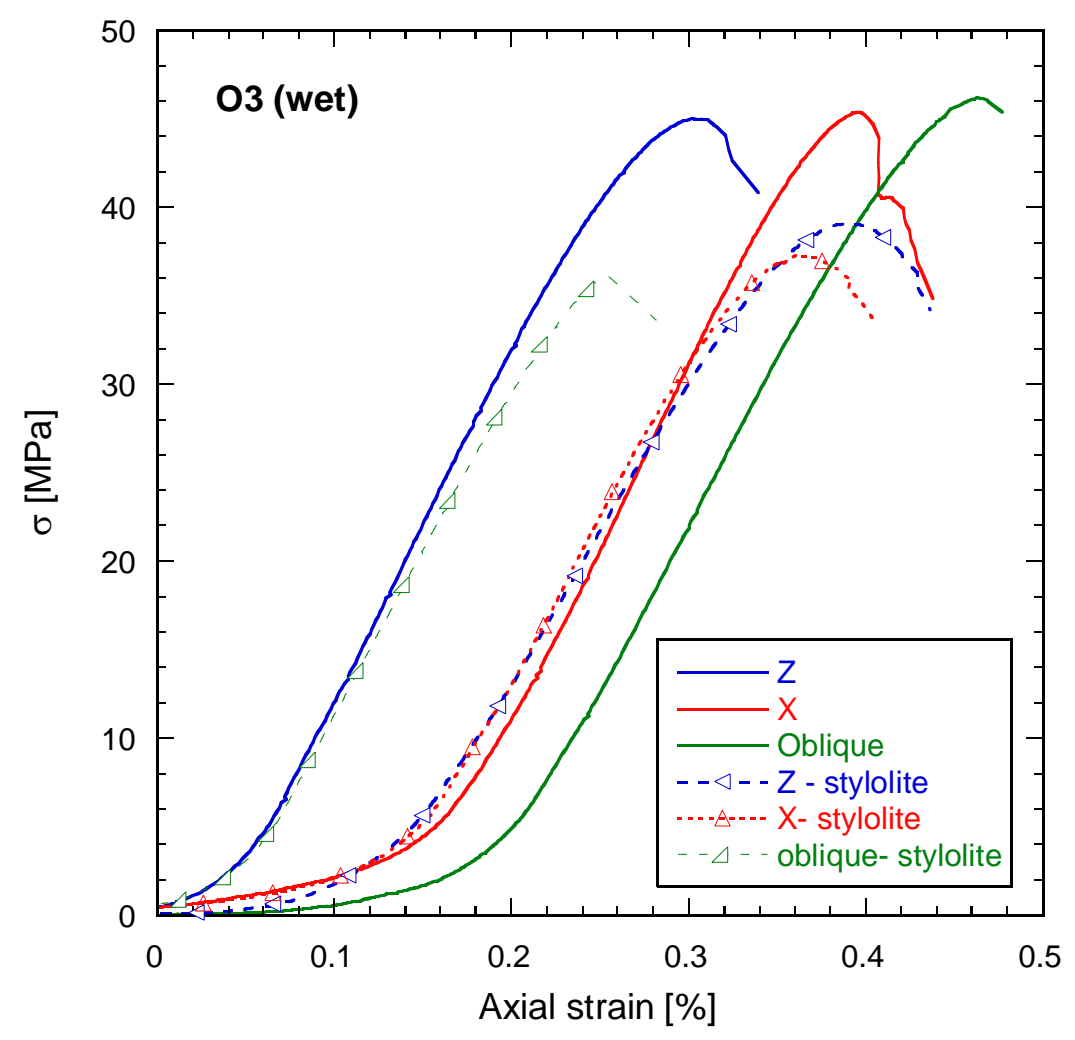


G)

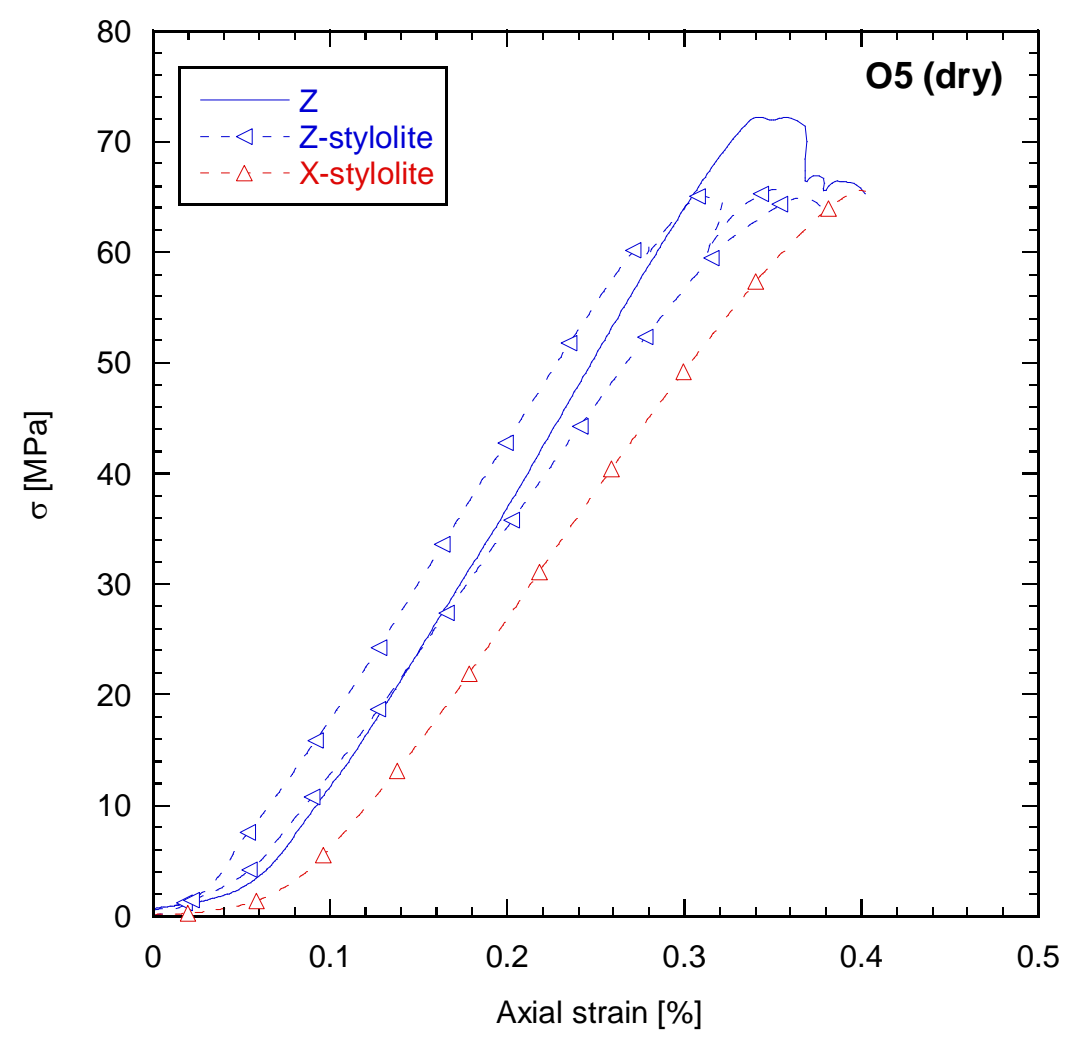

H)

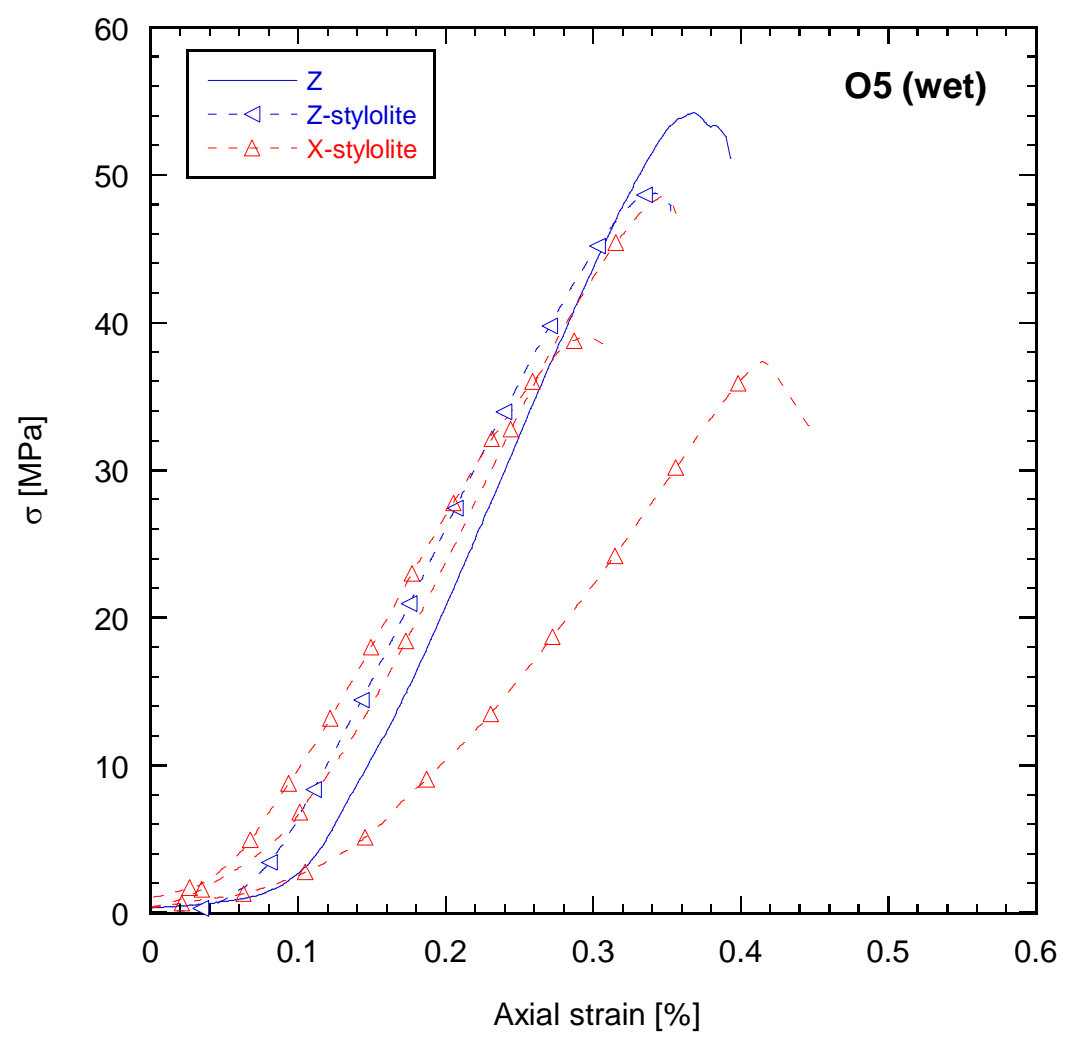


A)

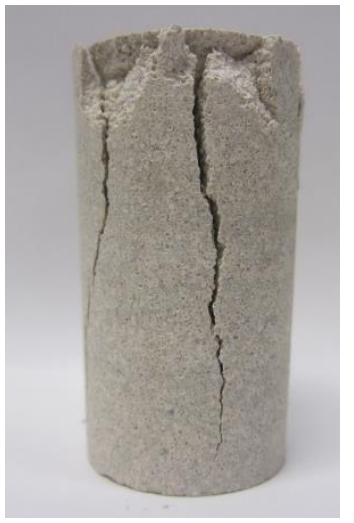

C)

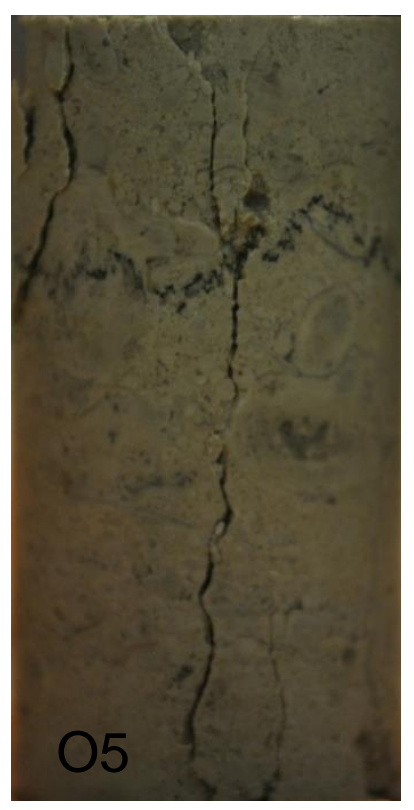

B)

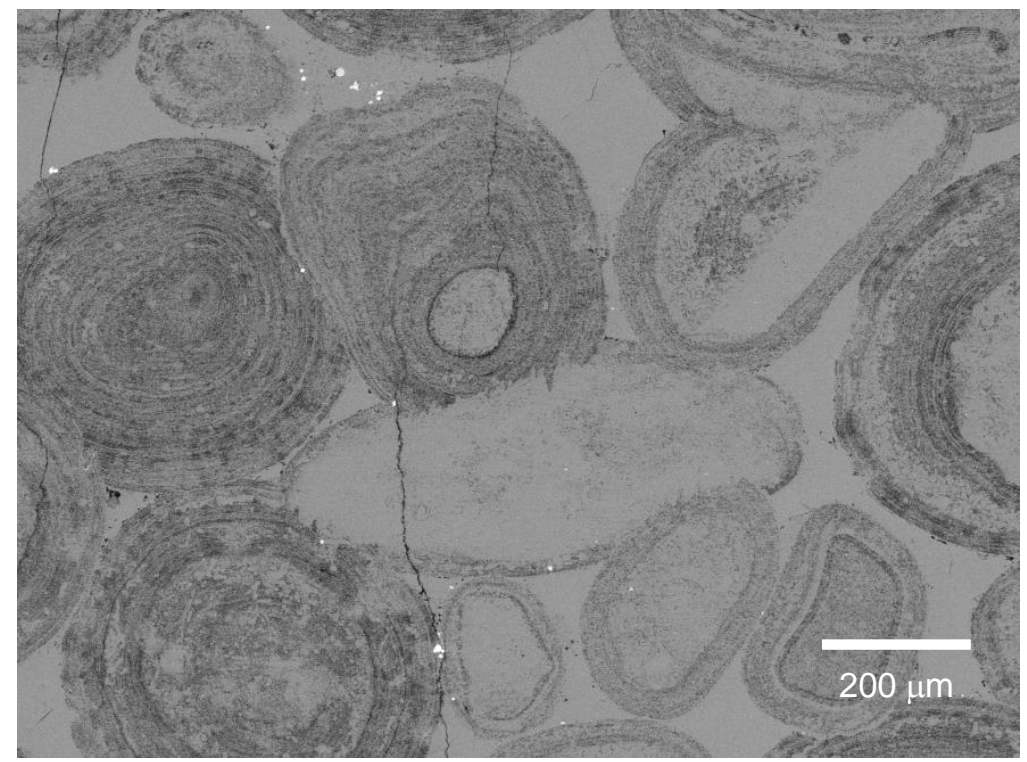

D)

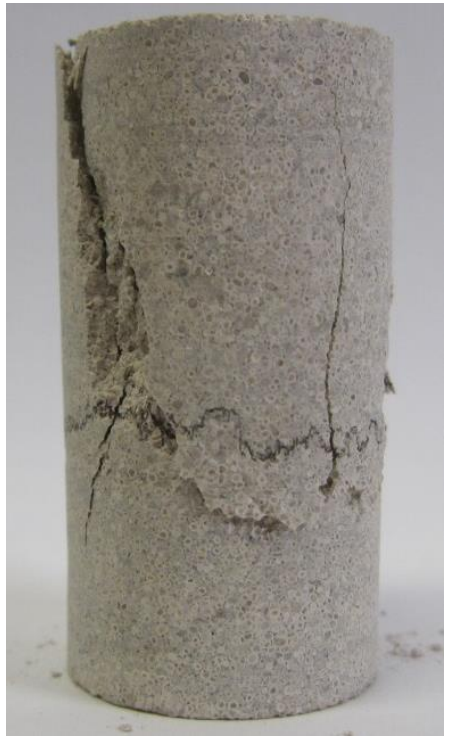

E)

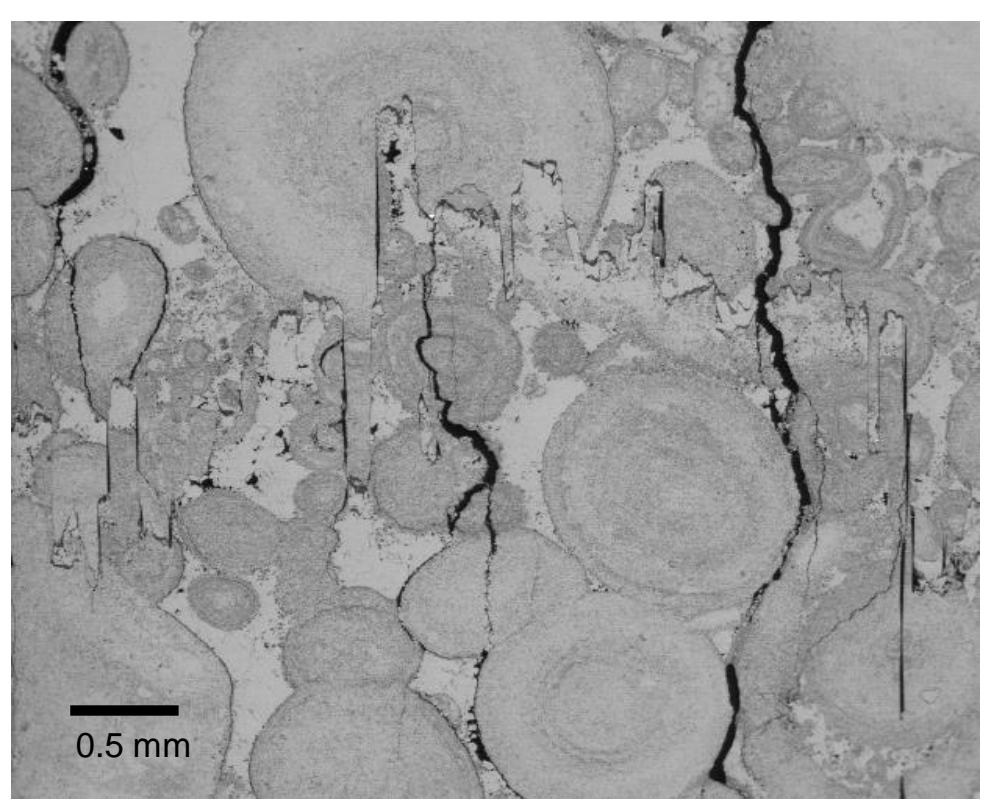

Figure 9 
A)

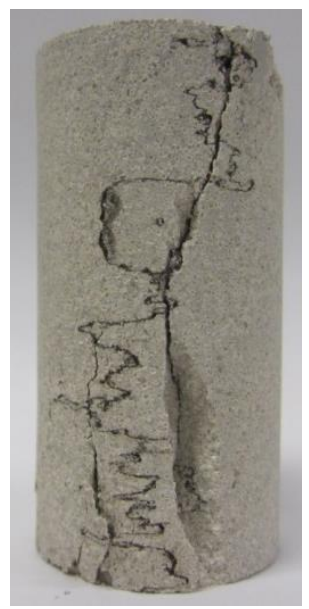

B)

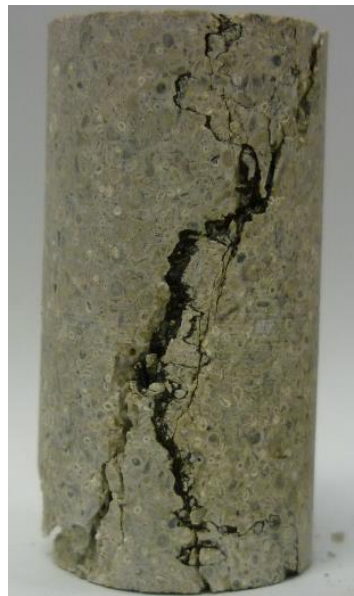

C)

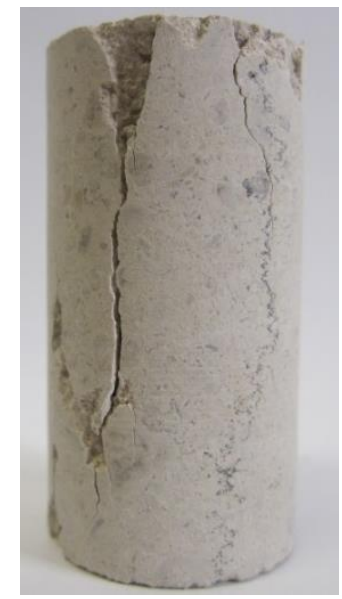

D)

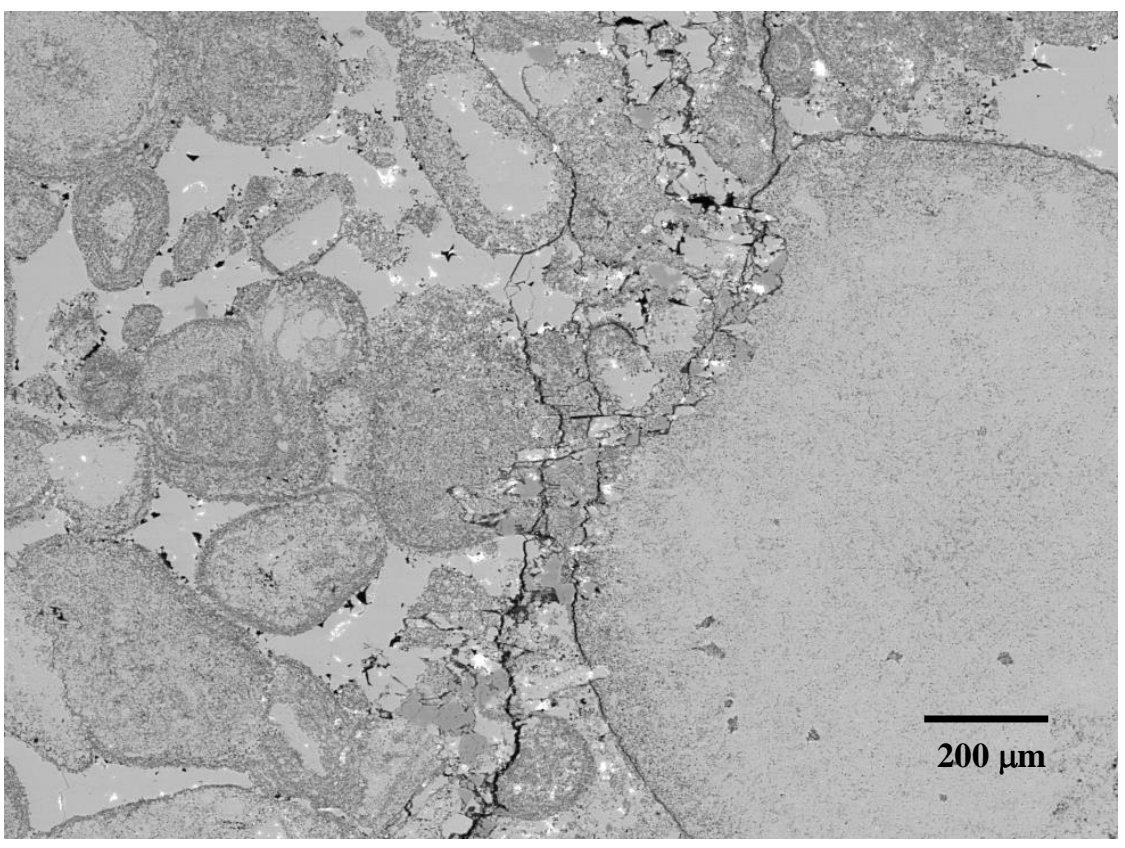

E)

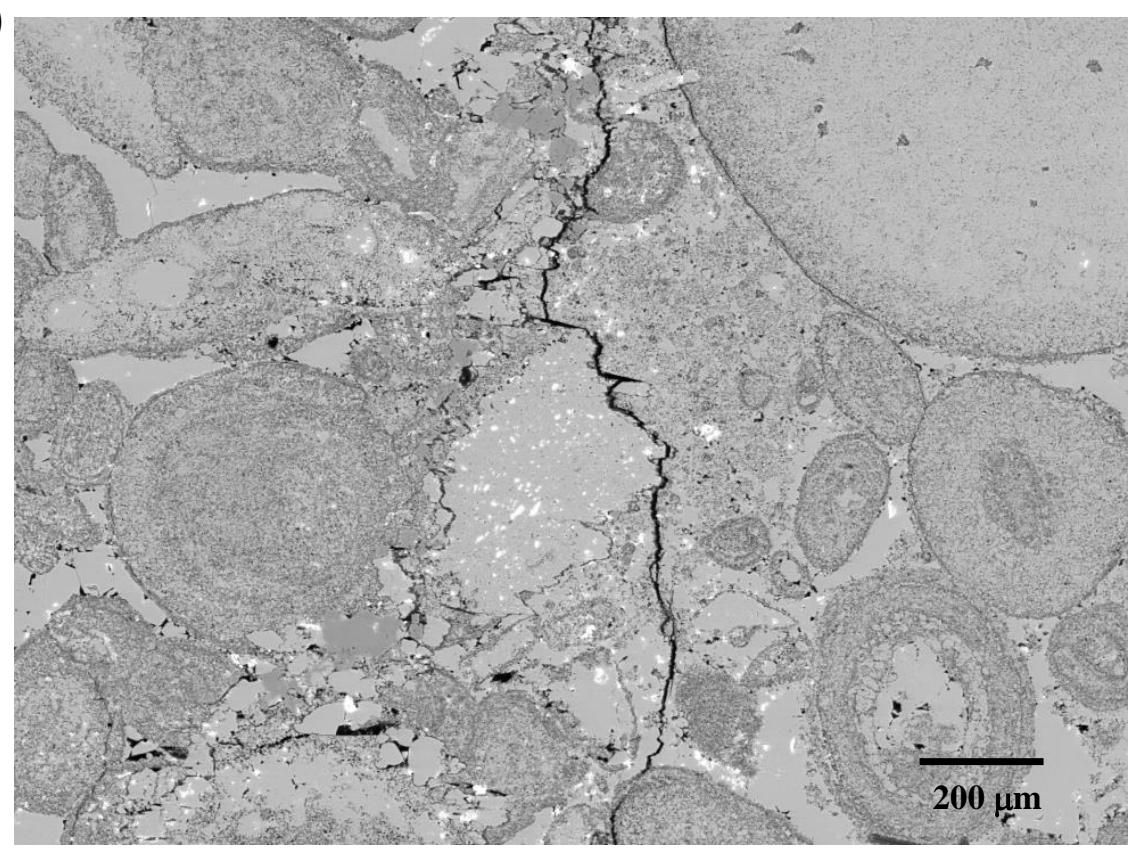

Figure 10 
A)

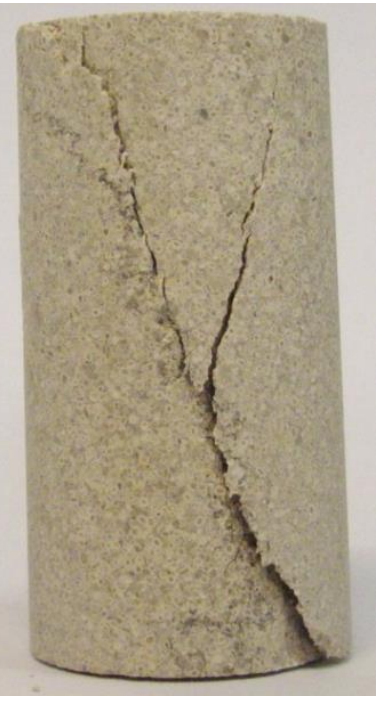

B)

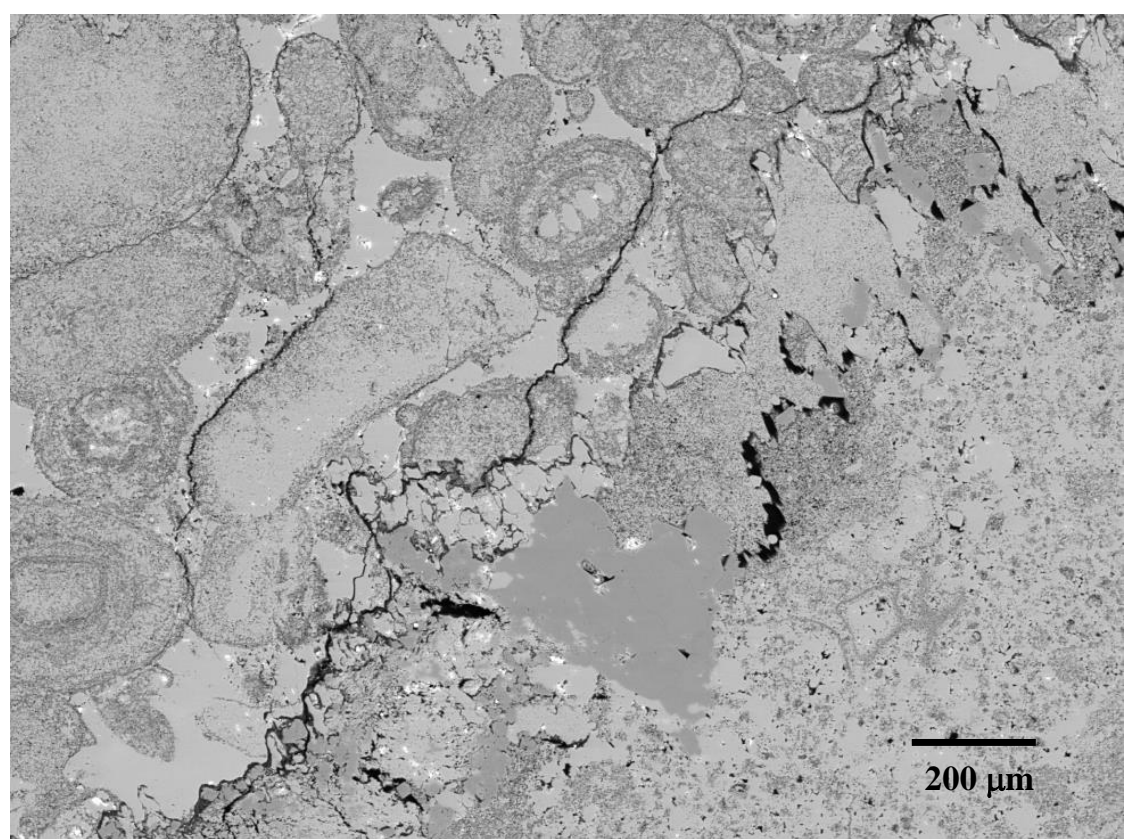

C)

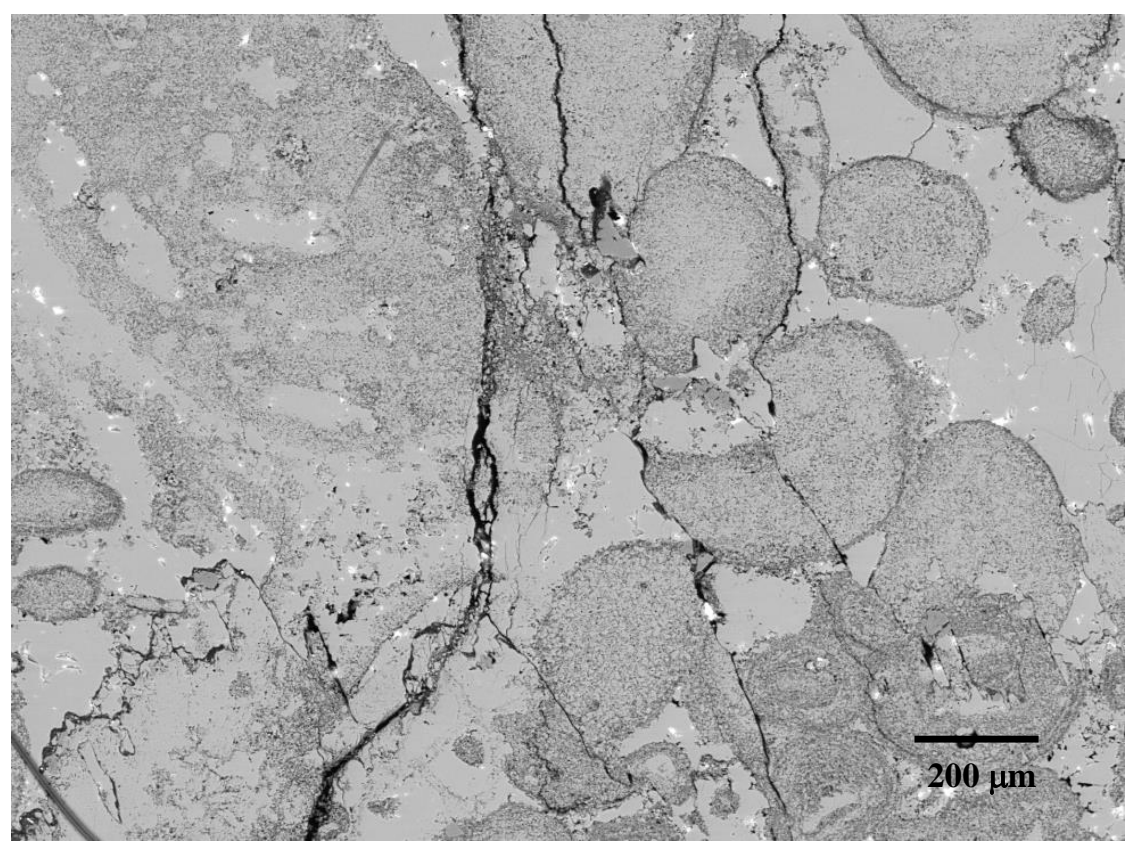

Figure 11 
A)

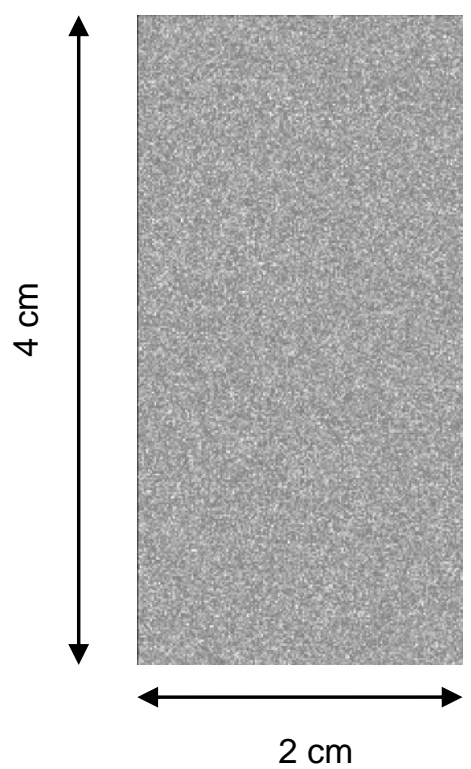

B)

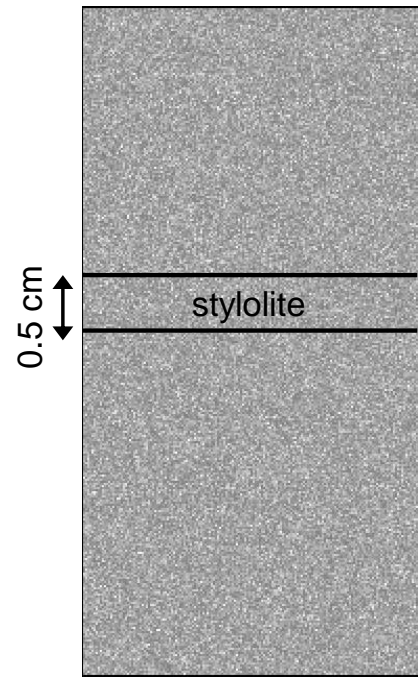

E)

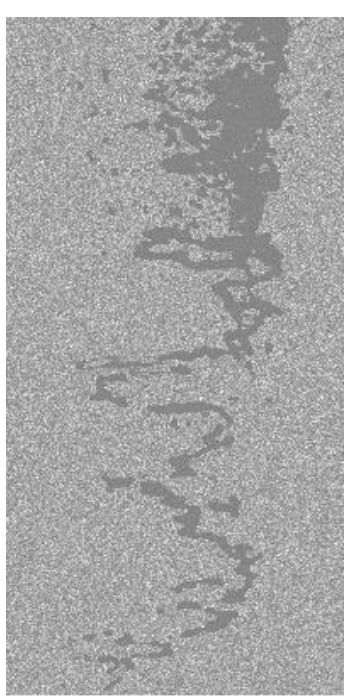

C)

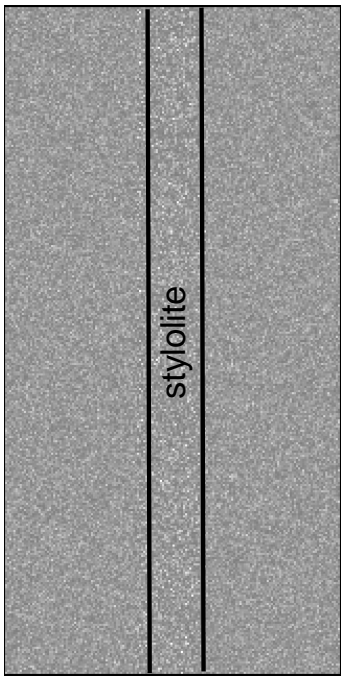

F)

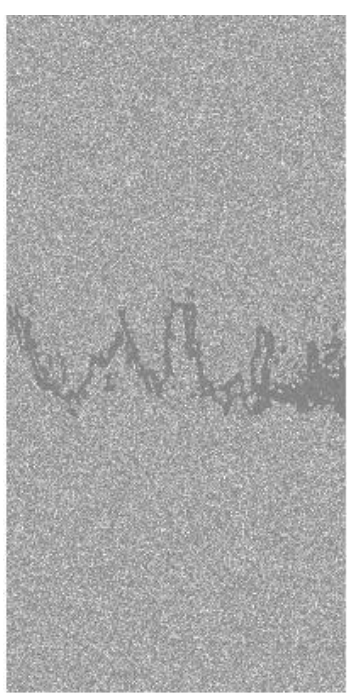

D)

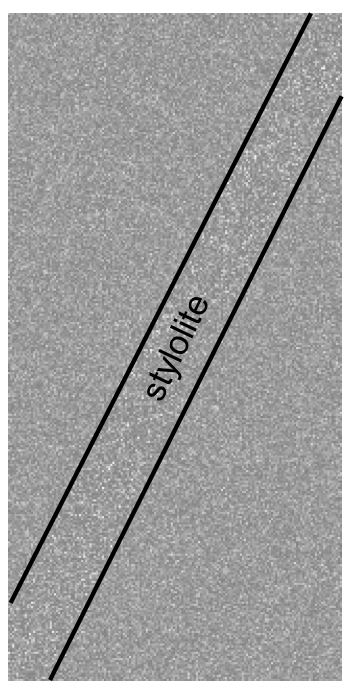

G)

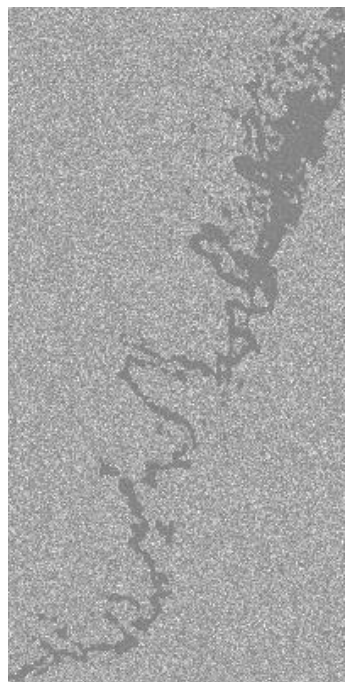

Figure 12 
A)

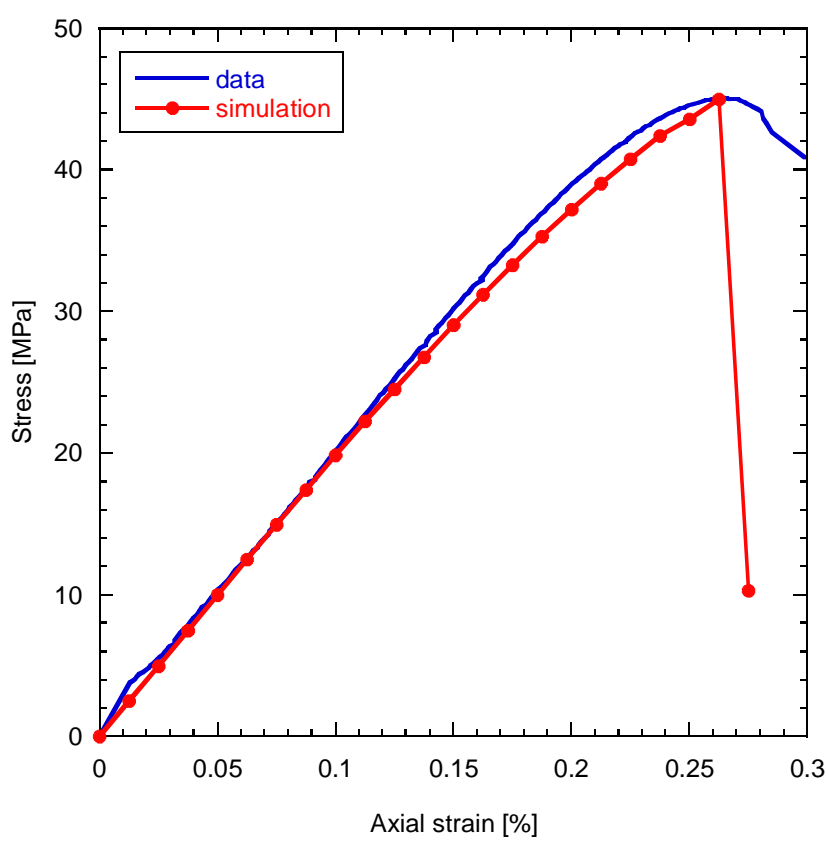

B)

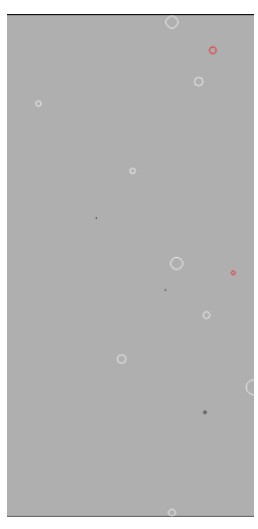

$0.08 \%$

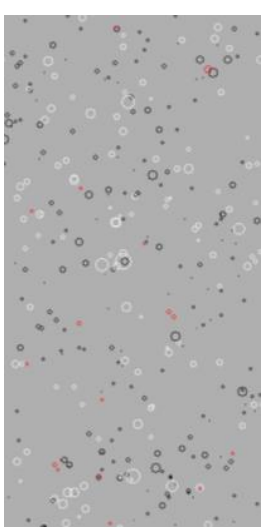

$0.13 \%$
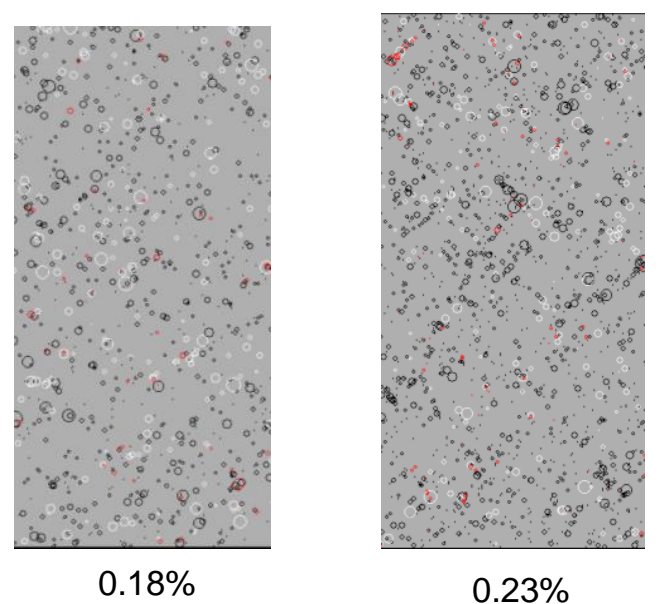

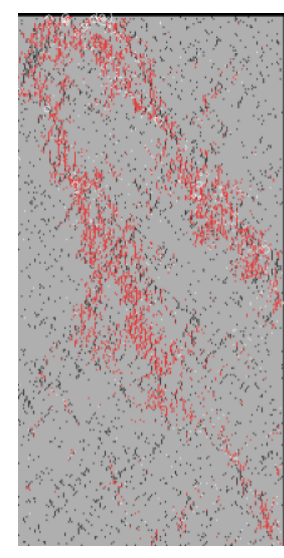

$0.28 \%$

Figure 13 
B)

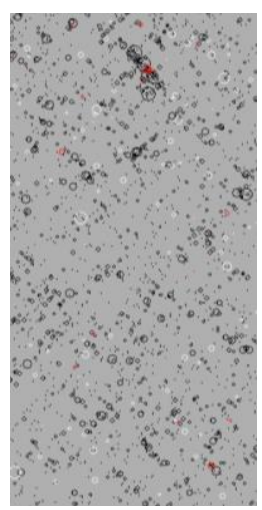

$0.08 \%$
A)

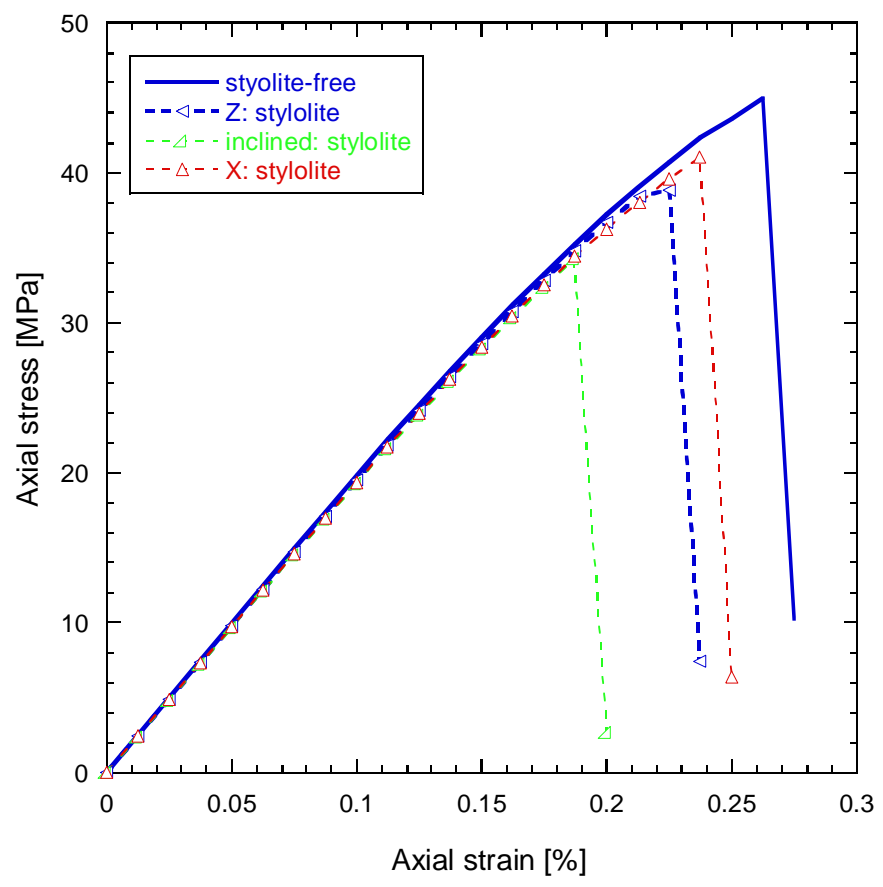

C)

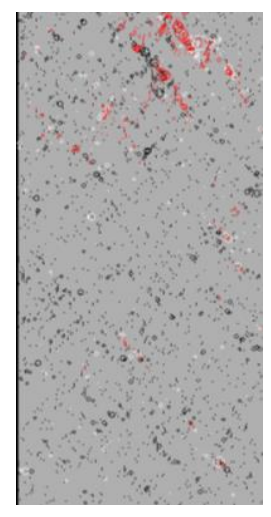

$0.13 \%$

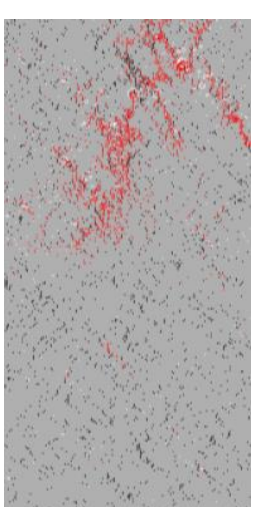

$0.18 \%$

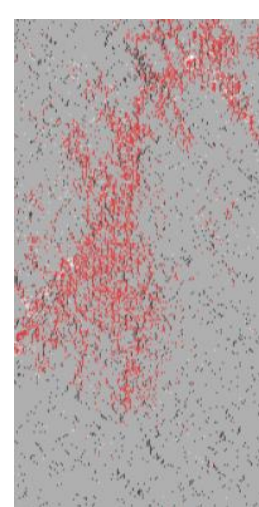

$0.23 \%$

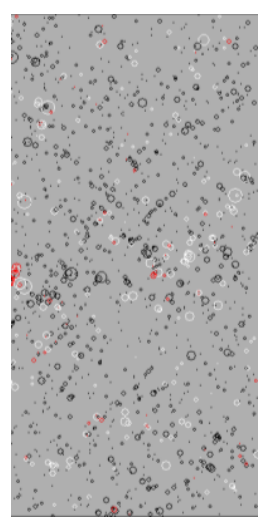

$0.08 \%$

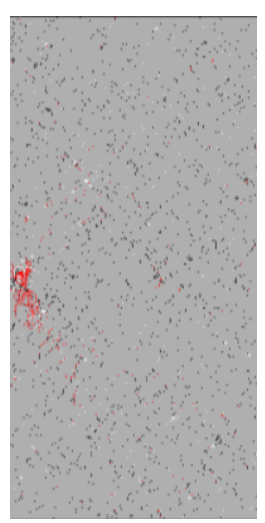

$0.13 \%$

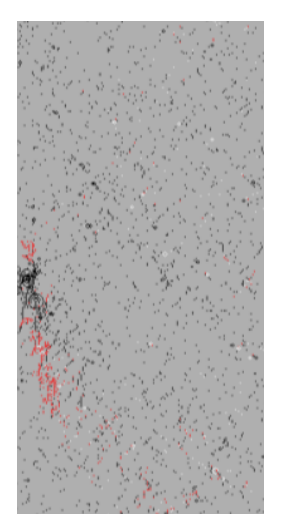

$0.18 \%$

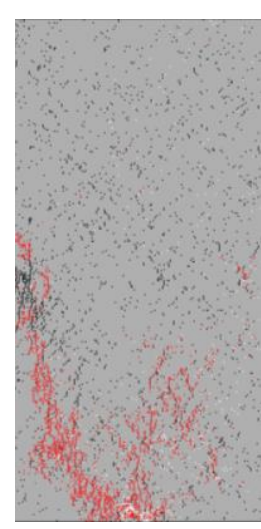

$0.23 \%$

Figure 14 
D)

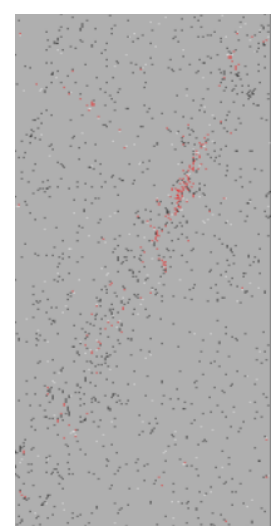

$0.08 \%$

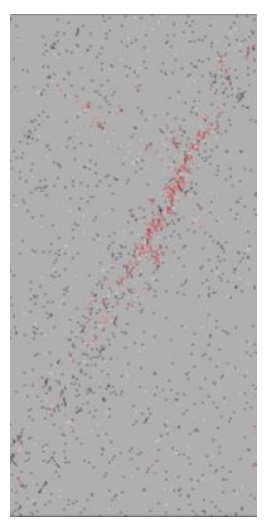

$0.13 \%$

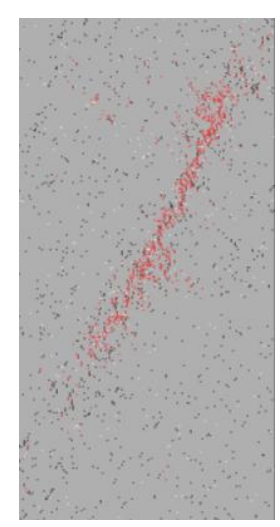

$0.18 \%$

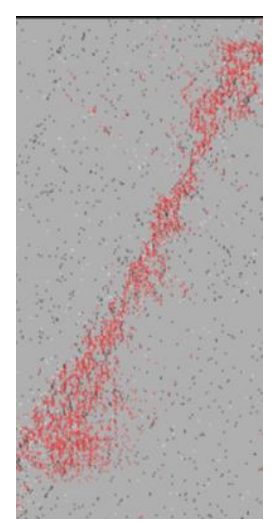

$0.23 \%$

Figure 14 
A)

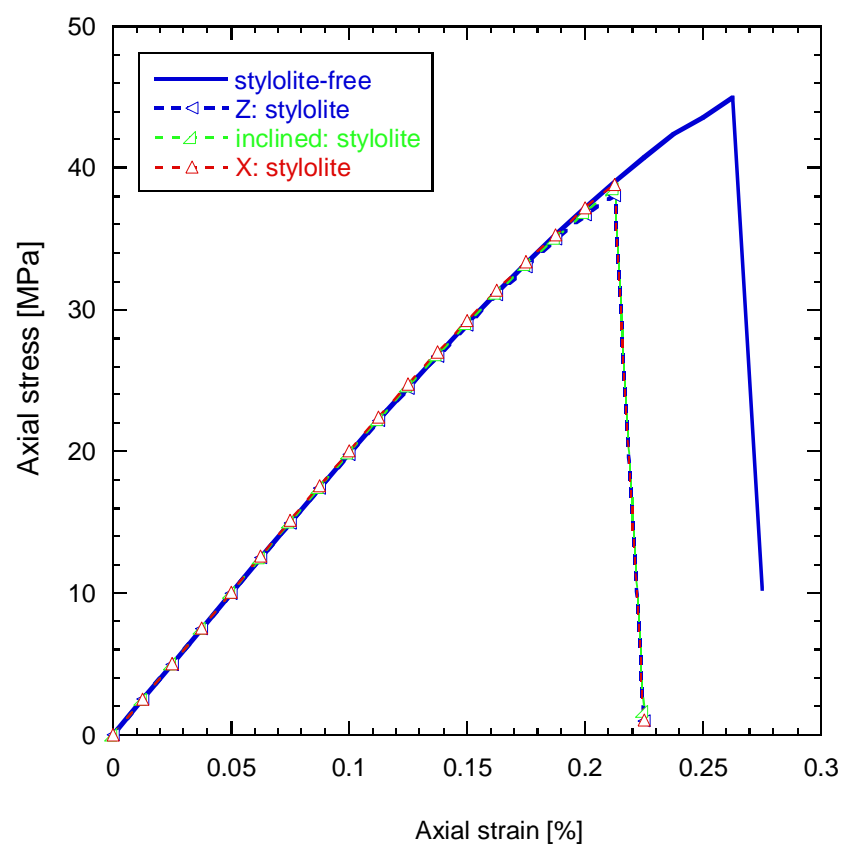

Figure 15 
B)

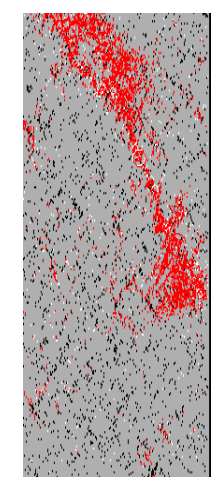

C)

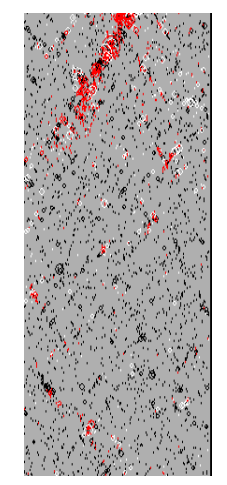

D)

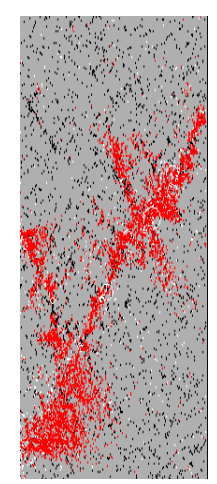

Figure 15 


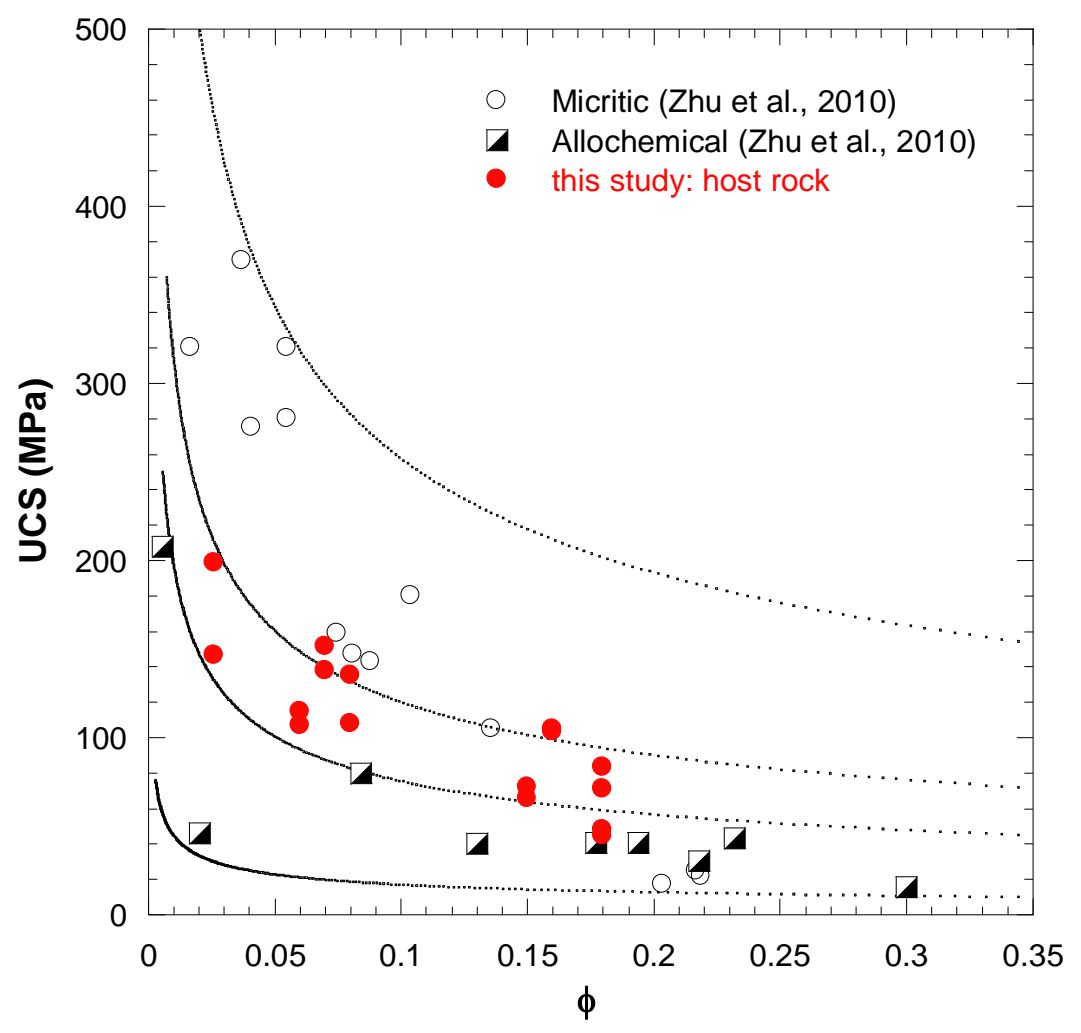

Figure 16 

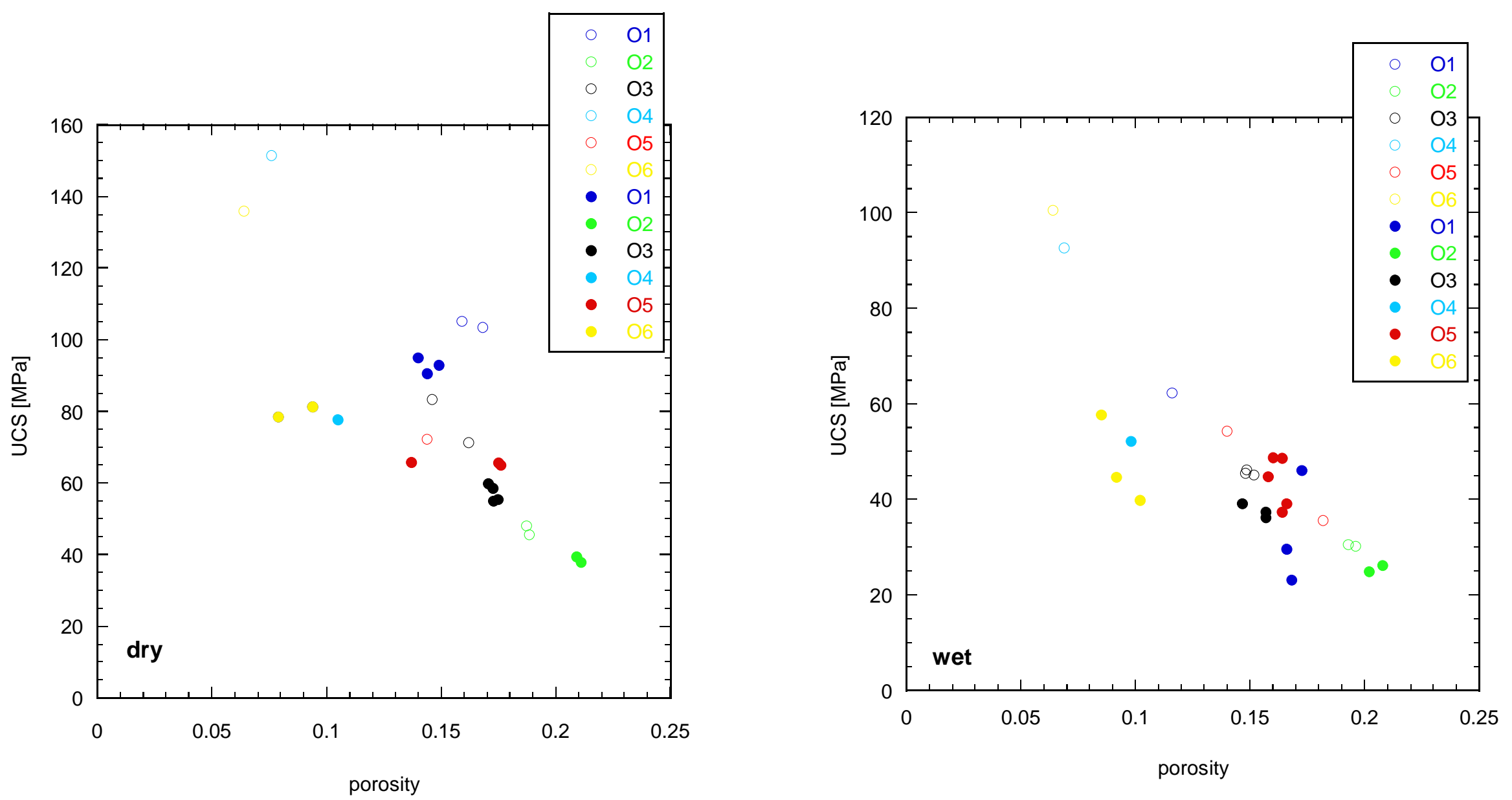

Figure 17 
A)

B)

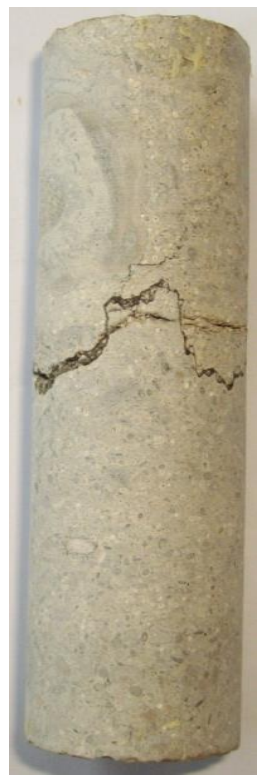

C)

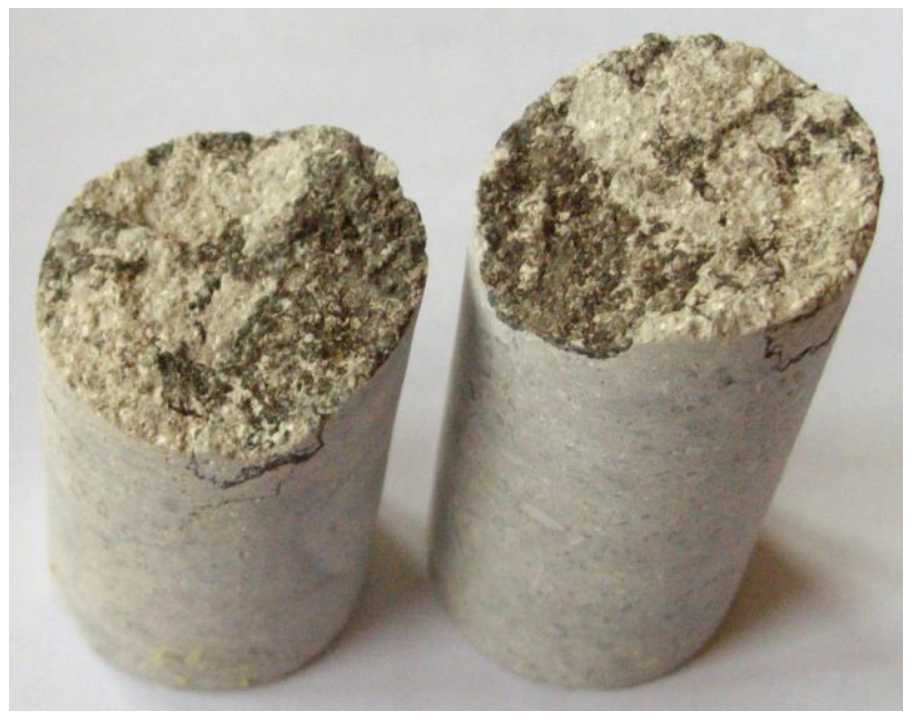

Figure 18 